\title{
1 Dissolved organic matter produced by Thalassiosira pseudonana
}

2 Krista Longnecker, Melissa C. Kido Soule, and Elizabeth B. Kujawinski*.

3 Woods Hole Oceanographic Institution, Marine Chemistry and Geochemistry, Woods Hole, MA

4 02543, U.S.A.

5 For submission to: Marine Chemistry

6 Date submitted: March 11, $2014 ; 1^{\text {st }}$ revised version submitted September 10, 2014, $2^{\text {nd }}$ revision

7 submitted October 28, 2014

8 Running title: Phytoplankton metabolomics

9 *Corresponding author. Mailing address: WHOI MS\#4, Woods Hole, MA 02543. Phone: (508)

10 289-3493. Fax: (508) 457-2164. E-mail: ekujawinski@whoi.edu

11 Keywords: metabolomics, marine phytoplankton, dissolved organic matter 


\section{Abstract}

Phytoplankton are significant producers of dissolved organic matter (DOM) in marine

15 ecosystems but the identity and dynamics of this DOM remain poorly constrained. Knowledge

16 on the identity and dynamics of DOM are crucial for understanding the molecular-level reactions

17 at the base of the global carbon cycle. Here we apply emerging analytical and computational

18 tools from metabolomics to investigate the composition of DOM produced by the centric diatom

19 Thalassiosira pseudonana. We assessed both intracellular metabolites within T. pseudonana (the

20 endo-metabolome) and extracellular metabolites released by T. pseudonana (the exo-

21 metabolome). The intracellular metabolites had a more variable composition than the

22 extracellular metabolites. We putatively identified novel compounds not previously associated

23 with $T$. pseudonana as well as compounds that have previously been identified within $T$.

24 pseudonana's metabolic capacity (e.g. dimethylsulfoniopropionate and degradation products of

25 chitin). The resulting information will provide the basis for future experiments to assess the

26 impact of T. pseudonana on the composition of dissolved organic matter in marine

27 environments. 


\section{Introduction}

Autotrophic microbes play a central role in the global carbon cycle because they fix

30 inorganic carbon into organic compounds. A fraction of this organic material is released into the

31 surrounding environment as dissolved organic matter (DOM), where it supports microbial

32 growth or is respired to carbon dioxide (del Giorgio and Cole, 1998; Kirchman, 2008). The rates

33 of utilization or remineralization of individual compounds are determined by their structure,

34 concentration, and the metabolic properties of ambient microorganisms (Azam and Worden,

35 2004). Thus, the molecular-level composition of DOM is an important factor in our

36 understanding of the global carbon cycle. Despite the significance of photosynthesis in the

37 production of organic matter, we know little about the molecular-level composition of

38 photosynthetically-derived DOM and the environmental factors that govern its production

39 (reviewed in: Carlson, 2002; Kujawinski, 2011).

Centric and pennate diatoms bloom in both coastal and open ocean settings where up to

$4140 \%$ of carbon fixation in marine ecosystems is attributed to these organisms (Nelson et al.,

42 1995; Tréguer et al., 1995). The centric diatom Thalassiosira pseudonana has received

43 significant attention as a laboratory model organism (Bowler et al., 2010). It was the first diatom

44 with a completed genome, although function could only be determined for half of the genes

45 (Armbrust et al., 2004). More recently, there have been genomic, transcriptomic, and proteomic

46 investigations of $T$. pseudonana which have revealed dynamic responses to growth state, light,

47 and nutrients (Dyhrman et al., 2012; Montsant et al., 2007; Norden-Krichmar et al., 2011; Nunn

48 et al., 2009; Shi et al., 2013). Yet our knowledge of T. pseudonana's impact on the composition

49 of organic matter in marine environments has not been well-explored. 
Metabolomics is an emerging analytical approach that seeks to characterize metabolites

51 produced by an organism during growth or released following cell death. In targeted

52 metabolomics, a limited set of known metabolites is quantified as a function of the process under

53 study. In contrast, untargeted metabolomics investigations (e.g., Böttcher et al., 2008; Long et

54 al., 2011) have no pre-defined list of metabolites and use qualitative, or semi-quantitative, mass

55 spectrometry to examine all possible features. Untargeted metabolomics datasets are immense

56 with thousands of resolved features, and informatics and statistical tools are employed to identify

57 the subset of biologically relevant compounds (Patti et al., 2012). Although complete

58 characterization is not feasible with available analytical methodologies, practitioners have used

59 electrospray ionization (ESI) mass spectrometry (MS) and nuclear magnetic resonance

60 spectrometry (NMR) to resolve and identify important molecules within plant systems (Iijima et

61 al., 2008; Quanbeck et al., 2012) and within model microorganisms such as Escherichia coli

62 (Rabinowitz and Kimball, 2007). These projects have provided valuable information on method

63 development and computational tools which have allowed detailed examinations of the chemical

64 interactions between biological entities and their habitats.

65 In the marine ecosystem, metabolic assessments of microorganisms have focused on

66 phytoplankton such as cyanobacteria (Baran et al., 2010; Bennette et al., 2011) and diatoms (Paul

67 et al., 2009). Experiments with these microbes have revealed that variability in phytoplankton-

68 derived metabolites can be linked to growth stage (Barofsky et al., 2009; Vidoudez and Pohnert,

69 2012), nutrient limitation (Bromke et al., 2013), and are affected by the presence of co-cultured

70 phytoplankton (Paul et al., 2009). Although recovery of targeted compounds has been used to

71 optimize metabolite extraction and analysis methods (Bennette et al., 2011), structural

72 characterization and identification of most metabolites remains challenging (Baran et al., 2010). 
The goal of this project was an exploration of the molecular-level composition of

74 metabolites produced by an autotrophic microorganism in order to characterize the metabolites

75 released into the marine environment as a result of photoautotrophic processes. We extracted

76 intracellular and extracellular metabolites from a laboratory culture of T. pseudonana and

77 examined their composition over time with liquid chromatography coupled to ultrahigh

78 resolution mass spectrometry (LC/FT-ICR-MS). Our analysis confirmed the presence of

79 metabolites previously identified as part of T. pseudonana's metabolic capacity as well as

80 specific metabolites not previously known to occur in T. pseudonana.

\section{Experimental section}

\section{$82 \quad 2.1$ Culturing Thalassiosira pseudonana}

The diatom Thalassiosira pseudonana (CCMP culture \#1335) was cultured axenically in

84 a modified version of L1 media made with an artificial salt solution (Turks Island Salts) with

85 extra silicate (212 $\mathrm{mol} \mathrm{L}^{-1}$ ) and $10 \mu \mathrm{mol} \mathrm{L}^{-1}$ selenous acid. The cultures were initiated by

86 adding $30 \mathrm{ml}$ of $T$. pseudonana in exponential growth to twelve flasks with an additional six

87 flasks serving as cell-free controls; each flask initially contained $300 \mathrm{ml}$ of media. The cultures

88 were incubated at $12^{\circ} \mathrm{C}$ under a $12 \mathrm{~h}: 12 \mathrm{~h}$ light:dark cycle. Samples were collected six hours into

89 the light cycle on days $0,1,3,7,8$, and 10 . Three flasks were destructively sampled at each time:

90 two replicates with T. pseudonana and one cell-free control. In order to characterize the temporal

91 variability in DOM and include cell-free controls, we could not accommodate more than two

92 replicates with $T$. pseudonana and the cell-free control for each time point.

\section{$93 \quad 2.2$ Ancillary samples}

94 At each time point, sample aliquots were removed for total organic carbon and nutrient 95 analyses, and for cell counts. Unfiltered water samples for total organic carbon were acidified to 
$96 \mathrm{pH}=2$ with $12 \mathrm{M}$ hydrochloric acid, and stored at $4^{\circ} \mathrm{C}$ until analysis on a Shimadzu TOC-V $\mathrm{V}_{\mathrm{CSH}}$

97 total organic carbon analyzer. The coefficient of variability between replicate injections was

$98<1 \%$. Comparisons to standards provided by Prof. D. Hansell (University of Miami) were made

99 daily to verify that the measured concentrations of the standard fell within the consensus values

100 for total organic carbon. The unfiltered water samples were also used to obtain concentrations of

101 nitrate + nitrite, ammonium, silicate, and phosphate using a Lachat Instruments QuickChem

1028000 continuous flow injection system. For cell counts, samples were fixed with 10\%

103 formaldehyde (final concentration) and stored at $-80^{\circ} \mathrm{C}$ until cells were counted using a Reichert

104 hemocytometer. The formaldehyde-fixed cells were also stained with DAPI and viewed with an

105 epifluorescence microscope to check for potential contamination by heterotrophic

106 microorganisms. Contamination was not observed at any time point during the experiment.

\section{$107 \quad 2.3$ Extraction of metabolites}

108 Our initial experiments testing different extraction and mass spectrometry methods

109 showed that extraction protocols appropriate for freshwater microorganisms such as a

110 methanol/chloroform extraction (Winder et al., 2008) cannot be readily applied to marine

111 organisms. The salt in seawater and the growth media is problematic for ESI mass spectrometry

112 because salt suppresses the ionization of the organic molecules. For this reason, we were not able

113 to analyze intracellular metabolites by direct infusion into the mass spectrometer. Rather, for

114 both intracellular and extracellular metabolites, we opted for a reversed-phase LC/FT-MS

115 method, in which salt co-elutes with the solvent front and is removed from compounds that are

116 retained on the chromatography column. We adapted existing extraction and analysis methods to

117 distinguish the organic compounds produced by T. pseudonana from the organic compounds in 
118 the growth media. The methods for extracting intracellular and extracellular metabolites

119 proceeded identically for the flasks with T. pseudonana and the cell-free controls.

The intracellular metabolites were extracted using a method developed by Rabinowitz

121 and Kimball (2007). Briefly, $1.5 \mathrm{ml}$ samples were centrifuged at $16,000 \mathrm{x} g$ at $4^{\circ} \mathrm{C}$ for 30 minutes

122 and the supernatant discarded. The resulting cell pellet was extracted three times with ice-cold

123 extraction solvent (acetonitrile:methanol:water with $0.1 \mathrm{M}$ formic acid, 40:40:20). The combined

124 extracts were neutralized with $0.1 \mathrm{M}$ ammonium hydroxide, dried in a vacufuge, and then re-

125 dissolved in $1 \mathrm{~mL}$ of 90:10 (v/v) water:acetonitrile for analysis on the mass spectrometer.

126 Prior to sampling the extracellular metabolites, the cells were removed by gentle vacuum

127 filtration through $0.2 \mu \mathrm{m}$ Omnipore filters (hydrophilic PTFE membranes, Millipore). Barofsky

128 et al. (2009) have observed filtration may release intracellular metabolites into the

129 exometabolome, and this potential bias must be considered in the discussion of our results. The

130 acidified filtrate was extracted using solid phase extraction with PPL cartridges (Varian Bond

131 Elut PPL cartridges) as previously described (Dittmar et al., 2008). After eluting with methanol,

132 the extracts were dried in a vacufuge, and then re-dissolved in $1 \mathrm{~mL}$ 90:10 water:acetonitrile

133 prior to analysis.

134 We quantified the extraction efficiency of the solid phase extraction resin in the

135 following manner. The water:acetonitrile solution was dried completely using a vacufuge and re-

136 dissolved in MilliQ water. The extract was then added to MilliQ water that had been acidified

137 with hydrochloric acid and analyzed on a Shimadzu TOC- $\mathrm{V}_{\mathrm{CSH}}$ total organic carbon analyzer as

138 described in section 2.2. The carbon concentration from the extract was compared to the

139 concentration of dissolved organic carbon in the filtrate to calculate the percent of organic carbon

140 retained by the PPL cartridges. 


\section{$141 \quad 2.4$ Analysis of metabolites}

All metabolomics analyses were conducted using liquid chromatography (LC) coupled by

143 electrospray ionization to a hybrid linear ion trap - Fourier-transform ion cyclotron resonance

144 (FT-ICR) mass spectrometer (7T LTQ FT Ultra, Thermo Scientific). Samples were stored at

$145-20^{\circ} \mathrm{C}$ until mass spectrometric analysis. Analysis of the extracts was conducted within 48 hours

146 of sample processing, except for the extracts from day three which were analyzed six days after

147 sample processing. LC separation was performed on a Synergi Fusion reversed-phase column

148 using a binary gradient with solvent A being water with $0.1 \%$ formic acid and solvent B being

149 acetonitrile with $0.1 \%$ formic acid. Samples were eluted at $250 \mu \mathrm{min}^{-1}$ with the following

150 gradient: hold at 5\% B for 0-2 min, ramp from 5 to 65\% B between 2 and 20 min, ramp from 65

151 to $100 \%$ B between 20 and 25 min, hold at 100\% B from 25-32 min, and then ramp back to 5\%

152 B between 32 and 32.5 min for re-equilibration (32.5-40 min). Both full MS and MS/MS data

153 were collected. The MS scan was performed in the FT- ICR cell from $m / z$ 100-1000 at 100,000

154 resolving power (defined at $400 \mathrm{~m} / \mathrm{z}$ ). In parallel to the FT acquisition, MS/MS scans were

155 collected at nominal mass resolution in the ion trap from the two features with the highest peak

156 intensities in each scan. Separate autosampler injections were made for analysis in positive and

157 negative ion modes.

158 Electrospray and mass spectrometry conditions were initially optimized by infusing a

159 mixture of metabolite standards in positive and negative ion modes. The list of compounds

160 within this solution and sample spectra are given in Fig.S1. The majority of these standards

161 preferentially ionize in either positive or negative ion mode. The LTQ FT Ultra was also

162 externally calibrated weekly using a standard mixture of caffeine (Sigma Aldrich), L-methionyl-

163 arginyl-phenylalanyl-alanine acetate (MRFA) (Sigma Aldrich), Ultramark 1621 (Alfa Aesar), 
164 acetic acid (Sigma Aldrich), sodium dodecyl sulfate (Sigma Aldrich), and sodium taurocholate

165 (Sigma Aldrich). The instrument has a mass accuracy of $<2$ ppm after external calibration.

\subsection{Processing of mass spectral data and feature identification}

Data were collected as XCalibur RAW files which were converted to mzXML files using

168 the msConvert tool within ProteoWizard (Chambers et al., 2012). Features were extracted from

169 the LC-MS data using XCMS (Smith et al., 2006), where a feature is defined as a unique

170 combination of a mass-to-charge $(\mathrm{m} / \mathrm{z})$ ratio and a retention time. Peak finding was performed

171 with the centWave algorithm (Tautenhahn et al., 2008), and only peaks that fit a Gaussian shape

172 were retained. Features were aligned across samples based on retention time and $\mathrm{m} / \mathrm{z}$ value using

173 the group.nearest function in XCMS; fillPeaks was used to reconsider features missed in the

174 initial peak finding steps. CAMERA was used (1) to find compounds differing by adduct ion and

175 stable isotope composition (Kuhl et al., 2012) and (2) to extract the intensities and $m / z$ values for

176 the associated MS/MS spectra. Finally, the list of features with their retention time, $m / z$ value,

177 and intensity from the extracted ion chromatographs (EIC peak heights) were exported to

178 MATLAB for further processing. Positive and negative ion mode data were processed as

179 separate datasets in XCMS and MATLAB.

In order to compare the data from the LC-based analysis with analyses generally done for

181 direct infusion ESI FT-ICR MS data, we calculated the elemental formulas for the $m / z$ values

182 from the mzXML files processed by XCMS. We used the Compound Identification Algorithm

183 developed by Kujawinski and colleagues (Kujawinski and Behn, 2006; Kujawinski et al., 2009)

184 with a formula error of $1 \mathrm{ppm}$, and a relationship error of $20 \mathrm{ppm}$. The mass limit above which

185 elemental formulas were assigned only by functional group relationships was $500 \mathrm{Da}$. Elements

186 considered are C, H, O, N, S, and P. These elemental formulas were then divided into compound 
187 classes that have been defined based on elemental ratios as approximated from data within

188 Hedges and Kim et al. (Hedges, 1990; Kim et al., 2003).

Several databases and in silico tools were consulted in order to make putative

190 identifications of select features from the untargeted metabolomics data. The databases included

191 the Madison Metabolomics Consortium Database (MMCD, Cui et al., 2008), METLIN (Smith et

192 al., 2005), and to a lesser extent MassBank (Horai et al., 2010), PubChem, and KEGG. The

193 database searches described in the present project allowed a 2 ppm window between the

194 measured and the database (calculated) $\mathrm{m} / \mathrm{z}$ values.

\section{$195 \quad 2.6$ Statistical analysis}

Non-metric multidimensional scaling (NMS) (Kruskal, 1964; Mather, 1976) was used to

197 analyze variability in metabolite composition. For this analysis, only the compounds that were

198 not found in the controls were considered; the list was not pruned to remove isotopologues or

199 adducts. Differences between individual samples were calculated based on the presence or

200 absence of features with the Bray-Curtis distance measure using the Fathom toolbox (D.L. Jones,

201 pers. comm.). The statistics toolbox in MATLAB was used to run the NMS analyses. The

202 dimensionality of the data set was assessed by comparing 40 runs with real data to 50 runs with

203 randomized data. Additional axes were considered if the addition of the axis resulted in a

204 significant improvement over the randomized data (at $p \leq 0.05$ ) and the reduction in stress was

205 greater than 0.05 . Stress is a metric of goodness of fit in NMS data, and thus large reductions in

206 stress indicate that the additional axis significantly improved the presentation of the data. The

207 proportion of variation represented by each axis was assessed by using a Mantel test to calculate

208 the coefficient of determination $\left(r^{2}\right)$ between distance in the ordination space and distance in the

209 original space. 
Model I regressions were used to quantify changes in EIC peak heights during the

211 experiment. The non-parametric Spearman’s rank correlation implemented in MATLAB was

212 used to test changes in compound classes, cell abundance, TOC concentration, and inorganic

213 nitrogen concentrations during the experiment.

\section{Results and Discussion}

\subsection{Using metabolomics to assess the impact of an organism on its chemical} $216 \quad$ environment Metabolomics seeks to describe and quantify metabolites produced by organisms in

218 response to their chemical microenvironment (Patti et al., 2012). To address this goal for the

219 centric diatom, T. pseudonana, we analyzed our untargeted metabolomics data in two ways.

220 First, we consider the pattern of shared metabolites in order to examine the similarities (or 221 differences) between samples or along a time series. These comparisons do not require

222 identification of unknown compounds; rather all detected intracellular and extracellular

223 metabolites can be compared over time. Second, the list of $\mathrm{m} / \mathrm{z}$ values was mined to obtain

224 putative compound identifications. While there is still need for increased coverage of

225 metabolomics databases (Kind et al., 2009), obtaining the identity of a compound greatly

226 expands our ability to understand the chemical impact of microbes such as diatoms. For example,

227 with a compound identification we can consider the environmental conditions that affect the

228 concentration of a metabolite, describe the biochemical pathways in which it occurs, and

229 examine the sources and sinks of this compound in the environment. This remains a major

230 challenge in environmental metabolomics, and is one that cannot be achieved solely within the

231 context of our work with T. pseudonana. In the following sections, we discuss the pattern of 
232 compounds produced by T. pseudonana and then the compounds that we were able to putatively

233 identify.

$234 \quad 3.2$ Temporal patterns in T. pseudonana metabolites

235 Over the course of the ten-day experiment, there were significant increases in the

236 abundance of $T$. pseudonana and the concentration of total organic carbon concurrent with

237 significant decreases in the inorganic nutrient concentrations (Spearman rank correlations, p-

238 values all $<<0.0001$, Fig. S2). The inoculum into the flasks with $T$. pseudonana resulted in the

239 transfer of organic compounds into the flasks at the beginning of this experiment as is apparent

240 in the higher total organic carbon concentrations observed at the first sampling point in the flasks

241 with T. pseudonana compared to the cell-free controls (Fig. S2). The cell-free controls did not

242 show statistically significant changes over time in cell abundance, TOC, or inorganic nutrient

243 concentrations (Spearman rank correlations, p-values $>0.05$ ).

244 We use two measures to compare our extracellular extracts with previous research on

245 dissolved organic matter. First, we consider the fraction of dissolved organic carbon that was

246 recovered with solid phase extraction. We recovered between 14 and $41 \%$ of the organic

247 compounds with the PPL cartridges, with increased extraction efficiencies at the later growth

248 stages of the experiment (Fig. 1). By comparison, Becker et al. (2014) recovered between 2 and

$24924 \%$ of dissolved organic carbon from their phytoplankton cultures, with variability in the

250 extraction efficiency correlated to phytoplankton phylogeny. Both studies observe efficiencies

251 below the 40-60\% extraction efficiency measured by Dittmar et al. (2008) for water samples

252 from marine and estuarine sites. Second, $m / z$ values from ultrahigh resolution mass spectrometry

253 data have previously been sorted into compound classes based on their elemental ratios (e.g.,

254 Bhatia et al., 2010; Minor et al., 2012). Using this approach, the DOM from T. pseudonana 
255 contains primarily protein-like, condensed hydrocarbon-like, and lipid-like compounds (Fig. 2);

256 with lignin-like and carbohydrate-like compounds comprising less than $1 \%$ of the assigned

257 elemental formulas. However, only a small fraction of the DOM could be sorted into compound

258 classes based on elemental formulas. The proteins, hydrocarbons, and lipids from the positive ion

259 mode data showed statistically significant increases with time; in negative ion mode, only the

260 correlation between proteins and sampling time was statistically significant (Spearman's rho, p-

261 values $<0.05$ ). While these compound classes do not distinguish between structural isomers, they

262 provide a means to compare the composition of different samples. Here, we show that increases

263 in T. pseudonana abundance are linked to higher numbers of protein-like, condensed

264 hydrocarbon-like, and lipid-like compounds. These broad classifications, however, also highlight

265 the limitations of analyses based on elemental formulas, which cannot distinguish between

266 structural isomers. As we will note in section 3.4, we observed instances of the same $\mathrm{m} / \mathrm{z}$ value at

267 different retention times, confirming the presence of structural isomers in this dataset.

268 The number of features detected within the sample extracts analyzed with our untargeted

269 metabolomics method showed slight variability during the course of the experiment (Table 1,

270 Fig. S3). The data summarized in Table 1 includes all unique combinations of an $m / z$ value and a

271 retention time; specific compounds will appear in this list multiple times if they were observed

272 with different adducts (e.g., $\mathrm{M}-\mathrm{H}^{+}$or $\mathrm{M}-\mathrm{Na}^{+}$) or with ${ }^{13} \mathrm{C}$ substitutions (i.e., isotopologues).

273 Almost 75\% of all features were observed only in the treatments with T. pseudonana and were

274 absent in the cell-free controls. The features found both in the treatments with T. pseudonana and

275 in the cell-free controls were not analyzed further.

276 Throughout the experiment, we detected more features in the exometabolome compared

277 to the endometabolome in both positive and negative ion modes (Fig. S3). There are several 
278 factors that contribute to this observation. First, a smaller volume of sample was processed to 279 obtain the intracellular metabolites. Thus, metabolites present at lower concentrations may not 280 have sufficient signal strength to be detected by the mass spectrometer. Second, methodological 281 constraints required us to use a different extraction method to assess the endometabolome 282 compared to the exometabolome. This might have affected the number and type of features 283 retained and likely impacted the patterns of features observed within the intracellular and 284 extracellular metabolite pools. The primary goal of extraction methods for both intra- and 285 extracellular metabolites is the capture of the broadest suite of compounds at sufficient 286 concentration and with minimal salt interference. Due to the different sample matrices, this 287 requires two different extraction methods. In the intracellular methods, simple cell lysis liberates 288 a diverse pool of compounds and salt removal occurs during the LC step. For extracellular 289 methods, compounds must be concentrated from the saltwater media, requiring the use of solid290 phase extraction resins. De-salting occurs at the same time as extraction in this method. The 291 method for the intracellular metabolites is optimal for low molecular weight compounds that are 292 more polar compared to the slightly less polar, moderate molecular weight compounds which are 293 captured by the PPL solid-phase extraction cartridges used for the extracellular metabolites.

294 Nevertheless the boundaries of polarity and molecular weight are not exclusive to each method, 295 and we expected overlap in the compounds observed in the intracellular and extracellular 296 metabolites extracted from T. pseudonana. Yet, only a small number of compounds (9 in 297 negative ion mode and 35 in positive ion mode) from T. pseudonana were observed in both the 298 intracellular and extracellular metabolites (Table 1). Whether or not this was due to changes in 299 the metabolites after they were exuded from the cells cannot be determined based on our current 300 data. Previous research has noted that filtration of diatom cells may cause intracellular 
301 metabolites to leak from cells which would bias characterization of extracellular metabolites

302 (Barofsky et al., 2009). Of the limited research that has been done into metabolites of marine

303 microorganisms, only two studies that we are aware of have attempted to examine both

304 intracellular and extracellular metabolites (Baran et al., 2010; Rosselló-Mora et al., 2008), and

305 neither of these studies assessed the overlap between the intracellular and extracellular

306 metabolites in their organisms.

Changes in the extracted-ion-current (EIC) peak heights can be a semi-quantitative

308 measure of the amount of a feature within a sample. EIC peak heights may vary because of (1)

309 variability in the mass spectrometer, (2) ionization efficiency of the different compounds, and (3)

310 the concentration of a compound within a sample. By definition, the present project took a finite

311 amount of time and we opted to analyze the samples a constant length of time after extraction in

312 order to minimize changes to the extract. This precludes analysis of the samples in a randomized

313 fashion, which would reduce the impact of instrument variability. An alternative option is to

314 group the sample extractions required for one project. This allows a pooled sample to be created

315 which can constrain differences in EIC peak heights that are due to analytical variability (Dunn

316 et al., 2011). Almost 9,000 features were observed in positive and negative ion mode and absent

317 from the cell-free controls (Table 1, Fig. S3). A fraction of these features showed significant

318 increases or decreases in EIC peak heights over the experiment (Table S1). More of the

319 extracellular metabolites showed increases in EIC peak heights over time compared to the

320 intracellular metabolites in both positive and negative ion modes (Table S1). Furthermore, a

321 higher percentage of features decreased over time in the extracellular compared to the

322 intracellular metabolites (Table S1). Such temporal variability over different growth stages in

323 extracellular metabolites released by T. pseudonana has also been noted by Barofsky et al. 
324 (2009). Yet, when all samples over the six sampling days were considered, the majority of

325 features did not exhibit statistically significant changes in EIC peak heights during the

326 experiment. The metabolites not exhibiting temporal variability could be compounds replenished

327 by T. pseudonana at a constant rate or compounds that are not affected by changes in the growth

328 conditions of the present project. While we cannot exclude the possibility that a subset of these

329 metabolites were transferred with the inoculum at the beginning of the experiment, these features

330 were absent from the controls and therefore not present in the media used to grow $T$.

331 pseudonana.

\subsection{Statistical analysis of occurrence patterns of metabolites}

We used NMS to analyze the pattern of features found in the intracellular and

334 extracellular metabolites. In positive ion mode, the NMS calculation (Fig. 3A and B) resulted in

335 an ordination with a final stress of 0.13 and $r^{2}=0.89$ with more variability on axis one than on

336 axis two $\left(r^{2}\right.$ on axis $1=0.66, r^{2}$ on axis $2=0.32$ ). In negative ion mode, the NMS calculation

337 (Fig. 3C and D) resulted in an ordination with a final stress of 0.12 and $r^{2}=0.78$ with more

338 variability on axis one than on axis two $\left(r^{2}\right.$ on axis $1=0.57, r^{2}$ on axis $\left.2=0.20\right)$. In both positive

339 and negative ion modes, the NMS revealed a larger variability in the intracellular metabolites

340 compared to the variability in the extracellular metabolites. In negative ion mode, this pattern

341 was predominantly due to differences observed in one replicate on days 1,8 , and 10 . This

342 variability between replicates sampled on days 1,8 , and 10 was also evident in positive ion

343 mode. We do not have an explanation for this inter-replicate variability for select days of the

344 experiment, but the fact that it was observed in both positive and negative ion modes suggests

345 either variability in biological activity or sample processing, and not analytical variability. The

346 positive ion mode data exhibited greater differences among samples collected at all of the time 
347 points. By day 7 of the experiment, the NMS revealed small changes in the composition of

348 extracellular metabolites as shown by the tight clustering of symbols for days 7, 8, and 10 in Fig.

349 3. This indicates that the composition of metabolites produced by T. pseudonana at the

350 conclusion of the experiment was less dynamic and fewer new compounds were being produced

351 compared to the more variable composition of metabolites observed during exponential growth.

\section{$352 \quad 3.4 \quad$ Annotating metabolites from T. pseudonana}

A major challenge with an untargeted metabolomics assessment is the task of fully

354 identifying the tens of thousands of features detected within a single dataset (Daly et al., 2014;

355 Schymanski and Neumann, 2013). In the ideal case, these identifications are validated using

356 authentic standards and multiple analytical methods coupled to iterative comparisons to different

357 databases (Sumner et al., 2007). This labor-intensive process currently renders identification of

358 the $\sim 18,000$ features found in the present project (Table 1) infeasible. Therefore, we culled our

359 dataset to focus attention on those compounds that would have the highest potential for

360 significant interest. To address our scientific goal of identifying compounds produced by $T$.

361 pseudonana and subsequently released into the environment, we focused our attention on

362 features detected in both intracellular and extracellular extracts. As described in the methods

363 section, we required a feature (a) to be absent from the cell-free controls, and additionally

364 required features (b) to be present in both replicates with T. pseudonana in order to increase our

365 confidence in the observation of each feature, and (c) to be present at more than one time point in

366 order to avoid considering transient features within the dataset. In the end, nine compounds in

367 negative ion mode and 35 compounds in positive ion mode (Table 1) met these stringent criteria

368 and we attempted to identify them based on exact mass and MS/MS data. 
We used an iterative process to annotate and putatively identify the compounds, with

370 comparisons to multiple databases. We used a classification scheme proposed by Sumner et al.

371 (2007) to rate the strength of our putative metabolite identifications (Table 2). The strongest

372 identifications, level 1, are those for which we have an authentic standard and have analyzed it

373 on our mass spectrometer. Level 2 identifications are putatively annotated without chemical

374 reference standards, but are based on spectral similarities with data from public or commercial

375 libraries. Compounds with only a match based on $\mathrm{m} / \mathrm{z}$ value are rated as level 3 classifications

376 within the Sumner et al. (2007) format. Finally, level 4 classifications are unknown compounds.

377 Searches based on comparisons of exact mass and the KEGG database have been previously

378 used to help characterize organic compounds (Longnecker and Kujawinski, 2011; Romano et al.,

379 2014; Suhre and Schmitt-Kopplin, 2008). Here, our first step in identification was comparison of

380 exact mass values with masses of metabolites present in METLIN. In addition, for features with

381 MS/MS fragmentation in our experiment, we compared our MS/MS spectra with METLIN

382 database spectra to assign a putative identification to the feature. However, not all compounds in

383 the METLIN database have associated MS/MS spectra. When no MS/MS data or matches to the

384 METLIN database were available for a selected feature, we consulted the MMCD database.

385 Finally, four of the features in positive ion mode were eliminated from consideration because the

386 features had the same $\mathrm{m} / \mathrm{z}$ value with different retention times, suggesting the presence of

387 structural isomers. Identifying these features would require analysis of authentic standards of

388 possible isomers to establish appropriate retention times and MS/MS data for comparison with

389 our experimental dataset. In the following sections we discuss the implications of the compounds

390 we were able to putatively identify (Table 2, Table S2). 


\subsection{Observation of compounds previously associated with T. pseudonana}

Chitin is produced by a variety of marine organisms, and crustacean shells are the largest

393 pool of chitin in the marine environment. After cellulose, chitin is the second most abundant

394 biopolymer on earth yet its low levels in marine sediments imply that it is readily recycled within

395 marine ecosystems despite its poor aqueous solubility (Gooday, 1990; Jeuniaux and Voss-

396 Foucart, 1991). In T. pseudonana, the chitin is found in the cell wall (Brunner et al., 2009;

397 Durkin et al., 2009) and flexible chitin fibers extend through the silica channels surrounding the

398 cell (Hildebrand et al., 2009). In the present project, we observed both tri-N-acetylchitotriose

399 (Fig. 4A) and chitobiose, which corroborates previous observations from culture experiments

400 with T. pseudonana (Smucker and Dawson, 1986). The extracted ion chromatogram of tri-N-

401 acetylchitotriose is shown in Fig. S4. The putative identification of tri-N-acetylchitotriose was

402 well supported because the METLIN database provided a match for its exact mass and a match

403 for the measured MS/MS spectra (Fig. 4B). Furthermore, the retention time for an authentic

404 standard matched the retention time measured in the culture experiment. The T. pseudonana

405 genome contains the synthetic pathway for chitin and 22 putative chitinases, which have a

406 potential for chitin degradation (Armbrust et al., 2004). One hypothesis is that T. pseudonana

407 degrades chitin to alter its sinking rate or to change the thickness of its cell wall to modulate the

408 influx of compounds (Armbrust et al., 2004). An alternate hypothesis is that T. pseudonana does

409 not express its chitinases for chitin degradation and that tri-N-acetylchitotriose and chitobiose are

410 lost from chitin fibers during cellular growth. This hypothesis is consistent with culture

411 experiments that did not reveal measurable levels of chitinase activity under different growth

412 conditions (Štrojsová and Dyhrman, 2008). However, this would not explain the presence of

413 multiple chitinases within the T. pseudonana genome. While we cannot distinguish between 
414 these two hypotheses with the present dataset, the observed increases in tri-N-acetylchitotriose

415 and possibly chitobiose suggest that the metabolic potential for chitin degradation in the genome

416 could be realized during the growth of $T$. pseudonana. This is a good example of a case where

417 genomic data are helpful in describing potential microbial metabolisms, yet metabolomics data

418 are required to quantify the actual metabolic processes active within marine environments.

As the experiment progressed, Thalassiosira retained increasing amounts of intracellular

420 dimethylsulfoniopropionate (DMSP; Fig. S5). DMSP was identified by exact $\mathrm{m} / \mathrm{z}$ matches in the

421 MMCD database and through analysis of an authentic standard. The identification of DMSP also

422 indicates that we were able to distinguish chemical compounds that are important in marine

423 environments, even with an untargeted metabolomics approach. DMSP is an organic sulfur

424 compound that can act as an osmolyte for marine phytoplankton (Kirst, 1990). In addition,

425 internal DMSP might scavenge potentially damaging reactive oxygen species or serve as a sink

426 for carbon during periods of unbalanced growth (Stefels et al., 2007). In T. pseudonana, the

427 production of DMSP is well-established (Keller et al., 1999) and increased amounts of DMSP

428 are produced when the cells are nitrogen-limited (Bromke et al., 2013; Bucciarelli and Sunda,

429 2003; Franklin et al., 2012). In the present project, we did not add DSMP to the media and we

430 did not detect DMSP in the cell-free controls. Yet, the amount of DMSP inside the cells

431 increased during the experiment which might reflect T. pseudonana's response to decreasing

432 nitrogen availability, although the concentration of inorganic nitrogen always remained above

$433600 \mu \mathrm{M}$ during the experiment (Fig. S2). While DMSP was observed at low levels in the external

434 metabolites, DMSP is not efficiently recovered by PPL cartridges and thus its detection in this

435 pool was likely underestimated significantly (W. Johnson, personal communication). The

436 amount of DMSP produced by different species of phytoplankton varies over several orders of 
437

438

439

440

441

443

444

445

446

447

448

magnitude, with diatoms having lower DMSP-to-carbon ratios than other phytoplankton (Stefels

et al., 2007). However, our observation and the recent observations by Franklin et al. (2012)

indicate that Thalassiosira may be important in the production of DMSP and therefore plays a role within the marine sulfur cycle.

\subsection{Identification of compounds not previously associated with T. pseudonana}

Compound identification is a major challenge in environmental metabolomics. In the

following discussion, we present putatively annotated features, but recognize that there is still

uncertainty associated with these identifications. Thus, a definitive identification will require

additional verification before we can hypothesize as to the role of these compounds within the

metabolism of T. pseudonana. Once we have confirmed the identity of these compounds, we can develop an appropriate quantitative assay and conduct laboratory experiments to address

hypotheses about the importance of these compounds in the chemical ecology of T. pseudonana.

The first compound is bryotoxin A, which could only be identified with exact $m / z$

matches in the MMCD database (Figure S6). While we collected an associated MS/MS

spectrum, there were no corresponding listings in METLIN or MassBank which could help

confirm the structure and identification. This compound is potentially interesting because it has

not previously been observed in marine systems and studies on its toxicity are limited to

experiments with cattle (McKenzie et al., 1987; McKenzie et al., 1989).

The second compound is a complex organic compound containing both iodine and

chlorine. The putative elemental formula for this feature is $\mathrm{C}_{22} \mathrm{H}_{22} \mathrm{Cl}_{2} \mathrm{I}_{2} \mathrm{~N}_{2} \mathrm{O}_{7}$ and we observed the feature primarily in the intracellular metabolites (Fig. 5). We observed the $\mathrm{m} / \mathrm{z}$ values of both

${ }^{35} \mathrm{Cl}$ - and ${ }^{37} \mathrm{Cl}$-isotopologues at the same retention time (Fig. S7), confirming the presence of

chlorine. Macroalgae are the primary source of halogenated organic compounds in marine 
ecosystems (Carpenter et al., 2000; Gschwend et al., 1985; Schall et al., 1994) and T.

461 pseudonana releases $\mathrm{CH}_{3} \mathrm{I}$, a simple organic halogenated compound (Hughes et al., 2006). Yet,

462 while T. pseudonana assimilates both iodide and iodate (de la Cuesta and Manley, 2009), to our

463 knowledge this is the first observation that T. pseudonana may produce a complex organic

464 compound containing both iodine and chlorine. In marine systems, between 40 and $90 \%$ of all

465 soluble iodine-containing compounds are organic compounds (Gilfedder et al., 2008; Lai et al.,

466 2011; Wong and Cheng, 1998), which play an important role in chemical ecology (Vanelslander

467 et al., 2012) and marine atmospheric chemistry (O'Dowd et al., 2002; Saiz-Lopez et al., 2011).

468 We also observed over one hundred features that were tentatively identified as peptides

469 (Table S3), mostly tripeptides (e.g., Arg-Tyr-Tyr) and a smaller number of dipeptides (e.g, Ala-

470 Pro). Matches to $\mathrm{m} / \mathrm{z}$ values in the METLIN database provide insight into the possible

471 combinations of amino acids that compose the peptides we observed. However, peptide

472 identification is challenging because (1) the amino acid sequence cannot be determined solely

473 based on exact mass and (2) there are structural isomers among the twenty possible amino acids

474 (He et al., 2004). While we will require additional analyses to identify the peptides we observed,

475 the prevalence of $m / z$ values matching peptides is noteworthy even without a putative

476 identification of the amino acid sequences. The peptides were primarily present in the external

477 metabolites, and were not always simultaneously present in the intracellular metabolite pool.

478 Furthermore, plots of the peptides’ EIC peak heights over time revealed statistically significant

479 increases in peak heights (Pearson correlation coefficients with $p<0.05$ ) for the majority of the

480 peptides (Table S3). This suggests that most of the peptides were increasing in concentration

481 over the course of the experiment. 
The unexpected observation of a large number of different peptides raises the question as

483 to why T. pseudonana releases so many different peptides and whether the peptides would be

484 readily assimilated by marine heterotrophic microorganisms. Free amino acids have been

485 quantified inside and outside of the cells in Skeletonema costatum cultures and they represented a

486 minor fraction (<5\%) of the released dissolved organic carbon (Granum et al., 2002). More

487 recently, a metabolomic investigation of Synechococcus revealed the presence of amino acids

488 and dipeptides both inside the cells and in the growth media (Baran et al., 2010). Thus, the

489 peptides we observe during T. pseudonana growth may be a product of protein turnover within

490 the cell which is subsequently released into the media. Dissolved peptides are easily hydrolyzed

491 to their constituent amino acids and then are rapidly consumed by heterotrophic microorganisms

492 (Hollibaugh and Azam, 1983; Kirchman and Hodson, 1986). As a result, any peptides released

493 by T. pseudonana are likely to have a short residence time in the marine environment. Further

494 work is needed to assess whether the peptides observed here will be consumed at different rates

495 depending on the carbon, nitrogen, and sulfur demands of the in situ heterotrophic bacterial

496 community.

497 Metabolomics lags far behind other 'omics' investigations and, until recently,

498 metabolomics research has focused on the development of laboratory methods, analytical

499 methods, and computational tools. In the present project we applied these emerging tools to

500 characterize the organic compounds that T. pseudonana may release into the environment.

501 Through this analysis we putatively identified compounds not previously associated with $T$.

502 pseudonana metabolism. While there have been only limited metabolomic investigations into the

503 impact of marine microorganisms on their chemical environment, the continued development of 
504 computational tools and establishment of new databases will be crucial in facilitating the

505 comparison of metabolites across organisms and ecosystems.

\section{Acknowledgments}

507 We thank the people at www.metabolomics-forum.com for answering questions about the

508 use of XCMS and CAMERA, Matthew Monroe at PNNL for information about data file

509 conversions, Erin Bertrand for discussions about the peptides, Paul Henderson for analyzing the

510 nutrient samples, and Winn Johnson for information about the analysis of DMSP. Comments

511 from the manuscript reviewers were much appreciated and helped clarify the presentation of the

512 project. Instrumentation in the WHOI FT-MS facility was funded by the National Science

513 Foundation MRI program (OCE-0619608) and by the Gordon and Betty T. Moore Foundation.

514 This work was supported by NSF grant OCE-0928424 to EBK. 


\section{Figure Legends}

517 Fig. 1. Extraction efficiency for the solid phase extraction of extracellular metabolites during the

518 course of the experiment. The extraction efficiencies for the treatments with $T$. pseudonana is the

519 percentage of the dissolved organic carbon retained by the PPL cartridges as a fraction of the

520 measured dissolved organic carbon in the filtrate.

521 Fig. 2. The number of (A) protein-like, (B) condensed hydrocarbon-like, and (C) lipid-like

522 compounds in the samples with $T$. pseudonana over the course of the experiment. The features

523 within the cell-free controls were removed from the dataset prior to calculating the elemental

524 formulas needed to define features based on their elemental ratios.

525 Fig. 3. NMS analysis based on presence or absence of features showing the differences in the 526 composition of organic matter analyzed in (A and B) positive ion mode and (C and D) negative

527 ion mode. The panels contain the same data coded differently to highlight (A and C) the

528 differences between intracellular and extracellular metabolites or (B and D) the sampling time

529 for the intracellular and extracellular metabolites.

530 Fig. 4. Changes in the (A) EIC peak height of a feature putatively identified as tri-N-

531 acetylchitotriose. Data from both replicates with T. pseudonana are shown in the figure. The

532 identification was based on $\mathrm{m} / \mathrm{z}$ value and (B) comparison of the MS/MS spectrum with data

533 available in METLIN. The structure of the compound is given within panel (A). The MS/MS

534 spectrum shown in (B) is that from our unknown feature and the table lists the $\mathrm{m} / \mathrm{z}$ values and

535 relative intensities given in METLIN.

536 Fig. 5. The organic compound potentially containing both chlorine and iodine was (A) observed

537 in negative ion mode as $[\mathrm{M}-2 \mathrm{H}+\mathrm{Na}]^{-}$. The structure of the compound as shown in PubChem is 538 given in (B). 
539 Longnecker, Kido Soule, Kujawinski

$540 \quad$ Fig. 1

541

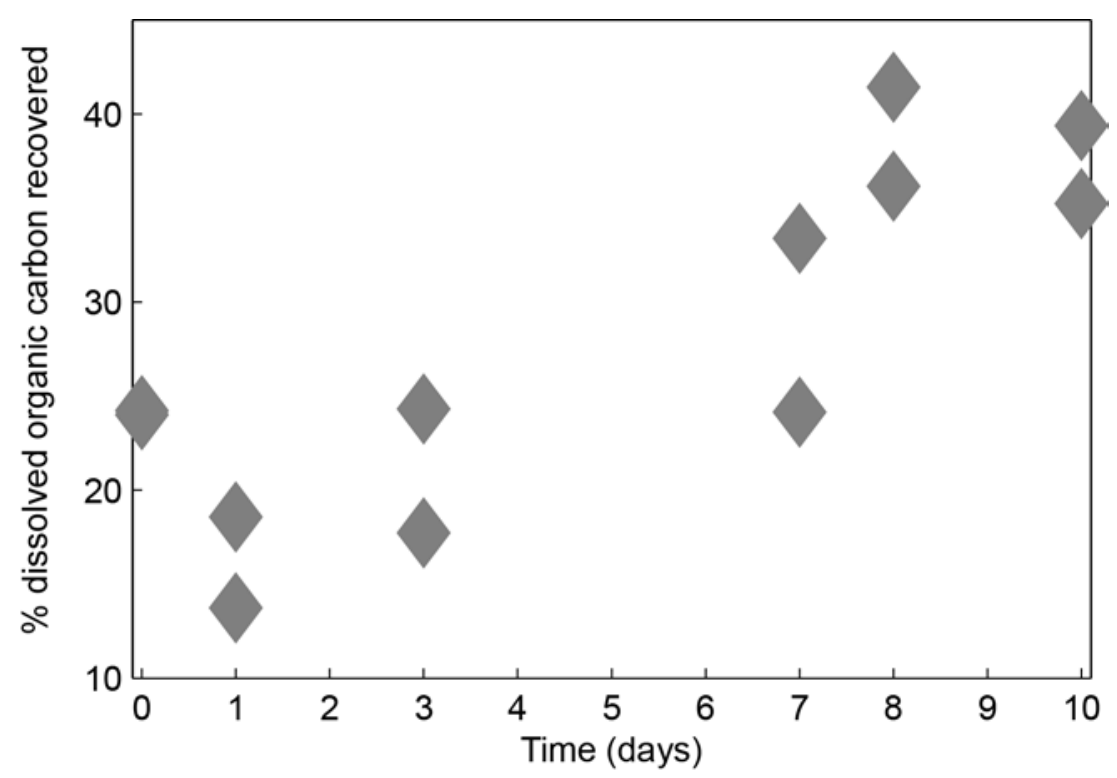


542 Longnecker, Kido Soule, Kujawinski

543 Fig. 2
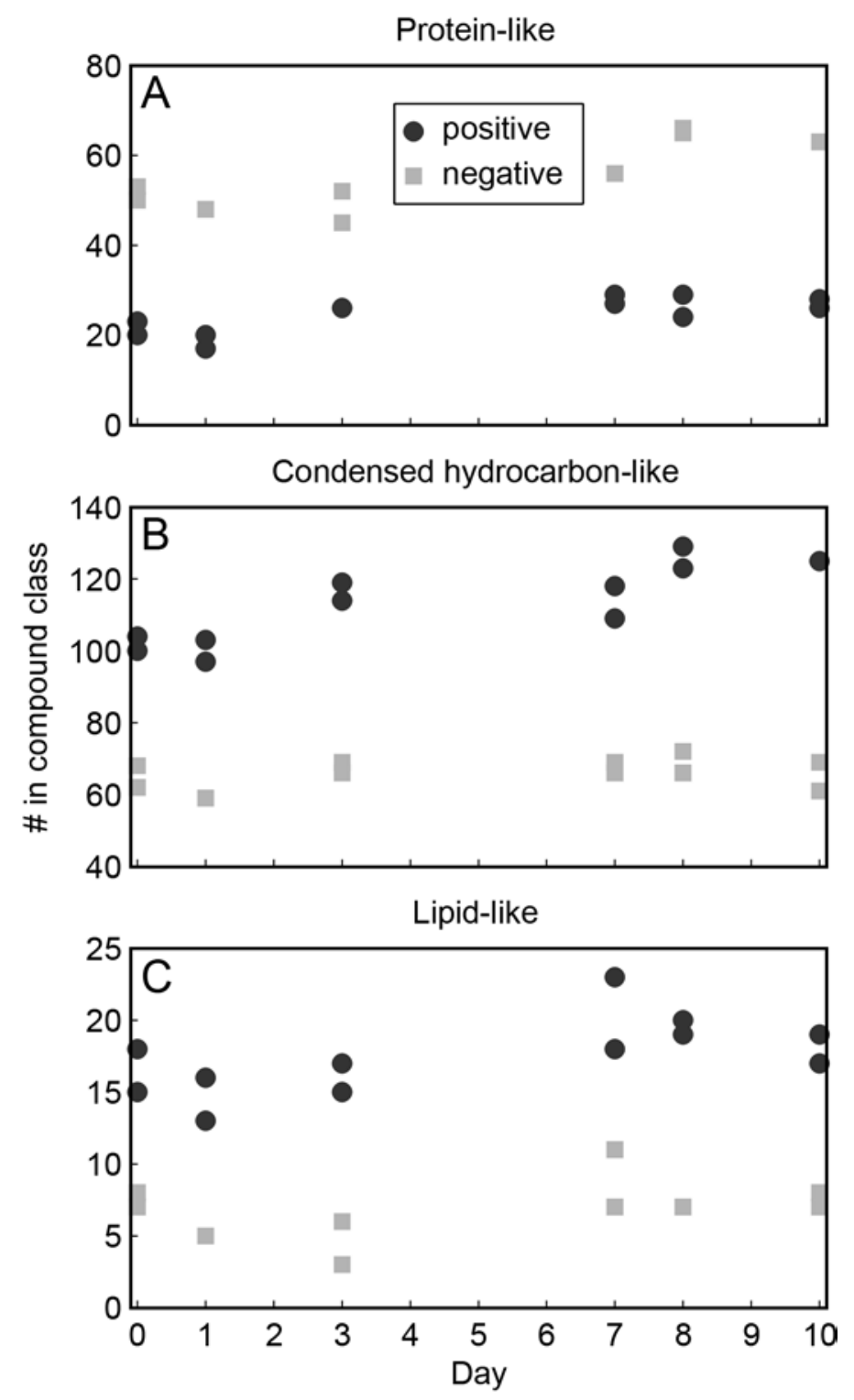
Fig. 3
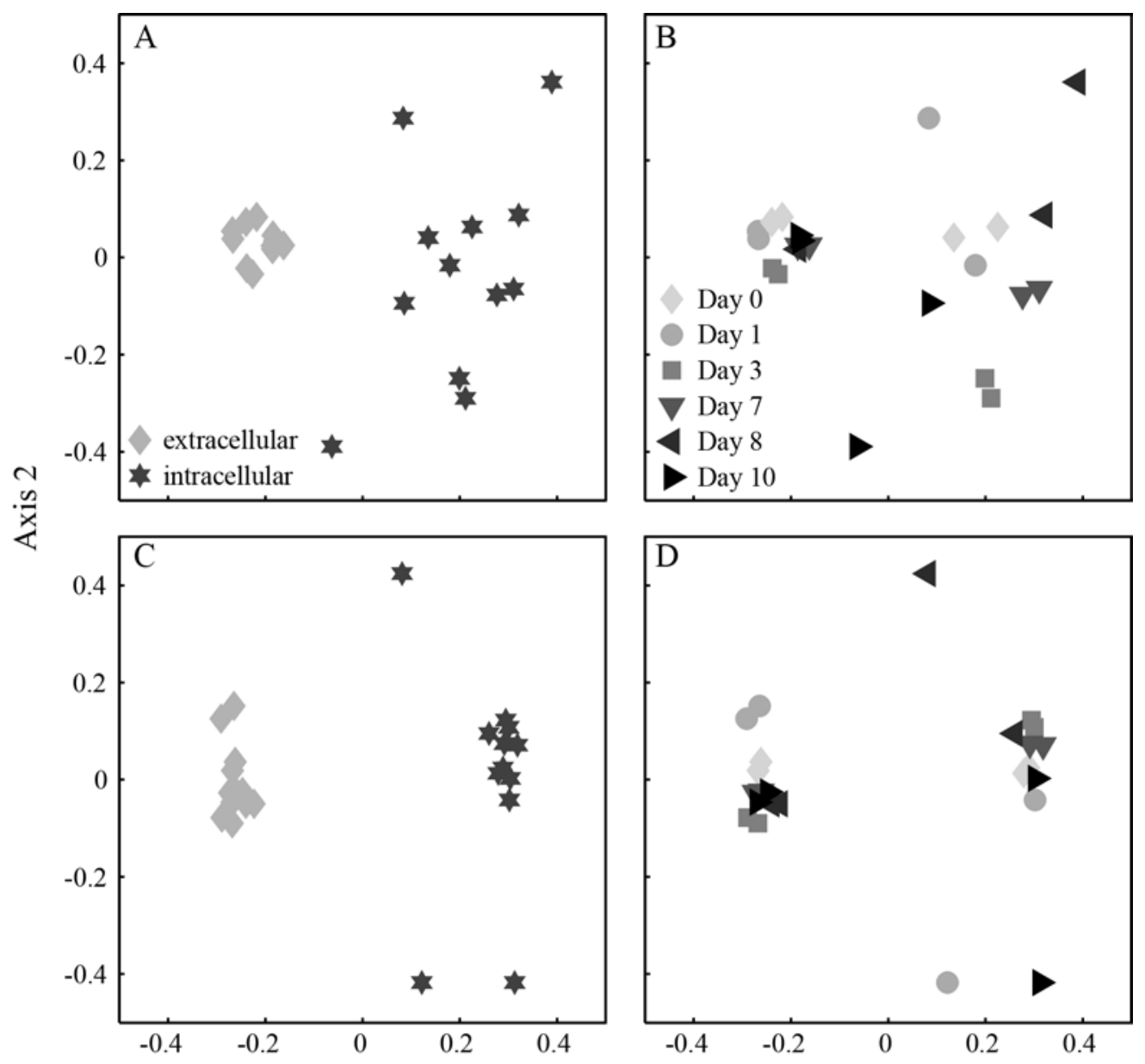

Axis 1 
Fig. 4
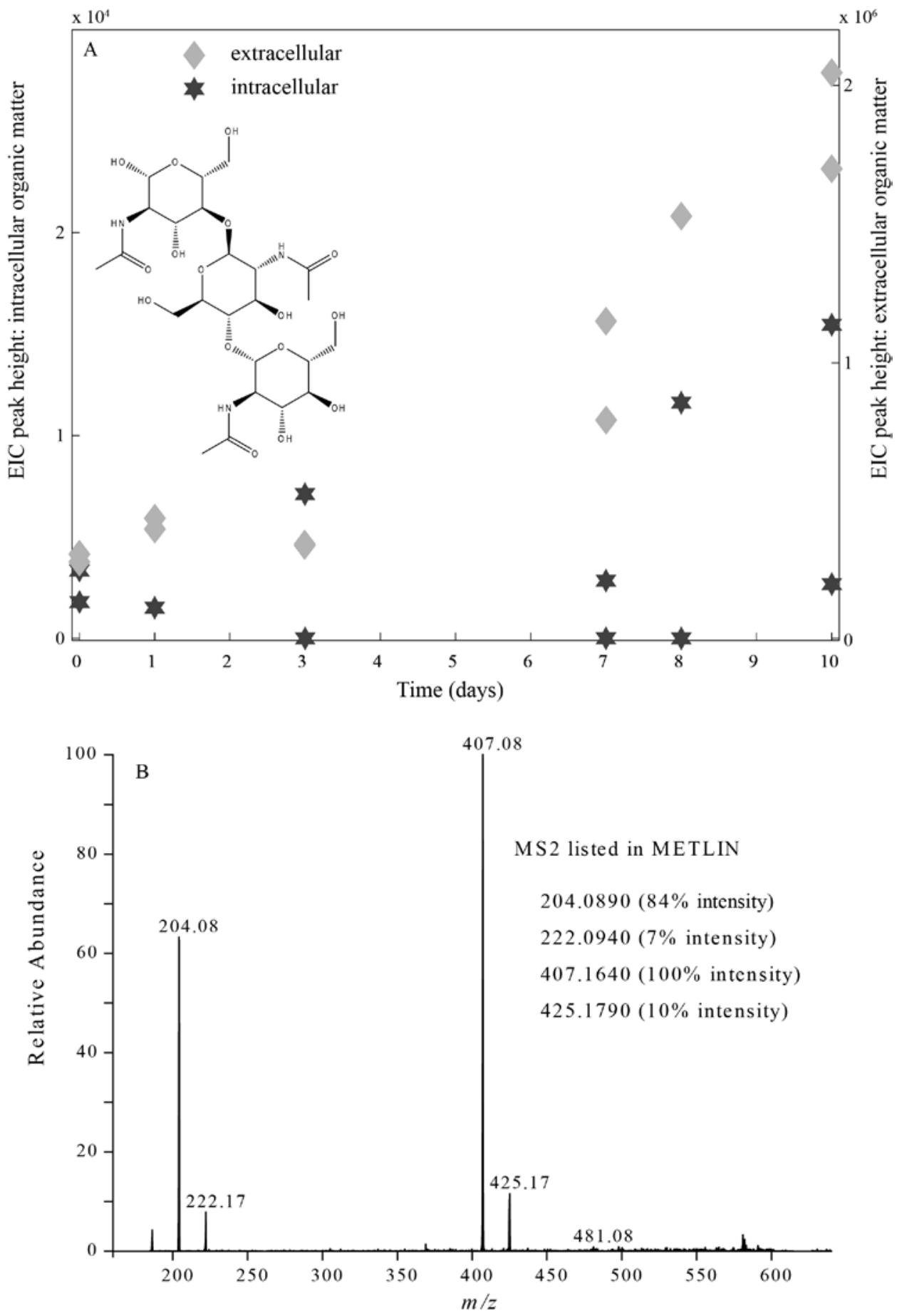
Fig. 5

551

552

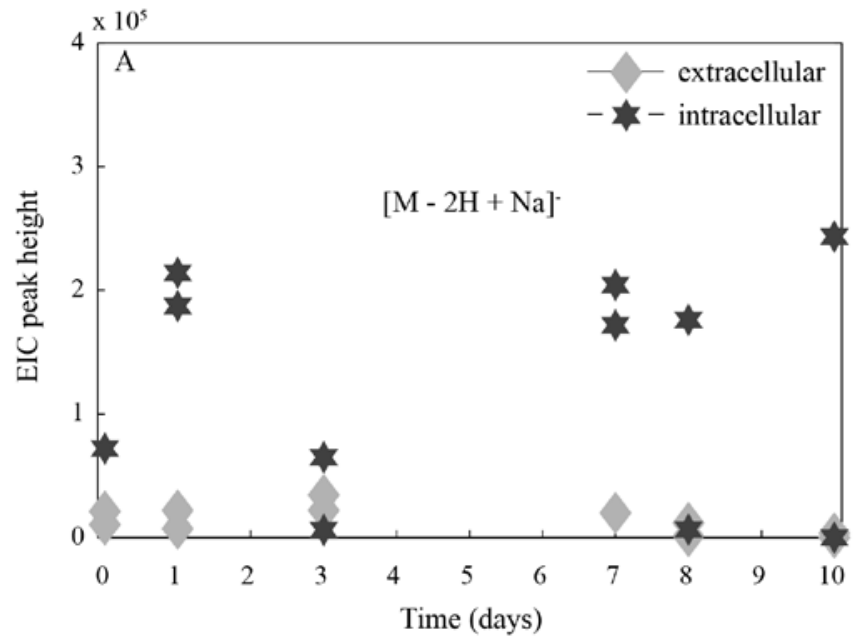

B<smiles>COC(=O)[C@H](NC(=O)[C@H](NC(=O)OC(C)(C)C)c1cc(Cl)c(Br)c(Cl)c1)c1cc(I)c(O)c(I)c1</smiles> 
553 Table 1. Summary of extracellular and intracellular metabolites exuded or retained by $T$.

554 pseudonana, as collected by LC/FT-MS in either positive or negative ion mode. Each feature is a 555 unique combination of an $m / z$ value and a retention time.

\begin{tabular}{lll}
\hline & Negative & Positive \\
\hline Total \# of unique features & 5484 & 12443 \\
\hline $\begin{array}{l}\text { Number (and percent) of features remaining after deleting } \\
\text { features found in the controls }\end{array}$ & $\begin{array}{l}4015 \\
(73 \%)\end{array}$ & $\begin{array}{l}9042 \\
(73 \%)\end{array}$ \\
\hline \# of features in the extracellular metabolites & & 2203 \\
\hline \# of features in the intracellular metabolites & 1630 & 3685 \\
\hline $\begin{array}{l}\text { \# of features found in both the intracellular and extracellular } \\
\text { metabolites }^{\dagger}\end{array}$ & 9 & 35 \\
\hline
\end{tabular}

$557 \quad{ }^{\S}$ Features present in both replicates of either the extracellular or intracellular metabolites.

$558{ }^{\dagger}$ Each feature had to be present in both replicates of the intracellular and extracellular metabolites 559 and present at more than one time point during the experiment. 
561 Table 2. Details on the compounds putatively identified in the experiments with T. pseudonana.

562 The table includes the information on the measured $\mathrm{m} / \mathrm{z}$ value and the ionization mode.

563 Additional details on each compound are presented in Table S2. Identification level is described

564 in the text and follows the convention proposed by Sumner et al. (2007).

\begin{tabular}{lllll}
\hline Putative annotation & $\begin{array}{l}\text { Measured } \\
\text { mass/charge }\end{array}$ & $\begin{array}{l}\text { Ionization } \\
\text { mode }\end{array}$ & $\begin{array}{l}\text { Reference } \\
\text { numbers }\end{array}$ & $\begin{array}{l}\text { Identification } \\
\text { level }\end{array}$ \\
\hline Tri-N-acetylchitotriose & 628.255600 & Positive & $\begin{array}{l}\text { PubChem CID } \\
444514\end{array}$ & 1 \\
\hline Chitobiose & 425.176513 & Positive & KEGG C01674 & 2 \\
\hline $\begin{array}{l}\text { Dimethylsulfoniopropionate } \\
\text { (DMSP) }\end{array}$ & 135.047394 & Positive & KEGG C04022 & 1 \\
\hline Bryotoxin A & 619.275800 & Positive & KEGG C08853 & 3 \\
\hline Organo-iodine compound & 770.865479 & Negative & $\begin{array}{l}\text { PubChem CID } \\
11535056\end{array}$ & 3 \\
\hline
\end{tabular}

565

566 
568 Armbrust, E.V., Berges, J.A., Bowler, C., Green, B.R., Martinez, D., Putnam, N.H. et al., The 569 genome of the diatom Thalassiosira pseudonana: ecology, evolution, and metabolism. Science 570 2004;306:79-86.

571 Azam, F. and Worden, A.Z., Microbes, molecules, and marine ecosystems. Science

572 2004;303:1622-4.

573 Baran, R., Bowen, B.P., Bouskill, N.J., Brodie, E.L., Yannone, S.M. and Northen, T.R., 574 Metabolite identification in Synechococcus sp. PCC 7002 using untargeted stable isotope 575 assisted metabolite profiling. Anal Chem 2010;82:9034-42.

576 Barofsky, A., Vidoudez, C. and Pohnert, G., Metabolic profiling reveals growth stage variability 577 in diatom exudates. Limnol Oceanogr Meth 2009;7:382-90.

578 Becker, J.W., Berube, P.M., Follett, C.L., Waterbury, J.B., Chisholm, S.W., DeLong, E.F. et al., 579 Closely related phytoplankton species produce similar suites of dissolved organic matter.

580 Frontiers in Microbiology 2014;5.

581 Bennette, N.B., Eng, J.F. and Dismukes, G.C., An LC-MS-based chemical and analytical method 582 for targeted metabolite quantification in the model cyanobacterium Synechococcus sp. PCC 583 7002. Anal Chem 2011;83:3808-16.

584 Bhatia, M.P., Das, S.B., Longnecker, K., Charette, M.A. and Kujawinski, E.B., Molecular 585 characterization of dissolved organic matter associated with the Greenland ice sheet Geochim 586 Cosmochim Acta 2010;74:3768-84.

587 Böttcher, C., Edda von, R.-L., Schmidt, J., Schmotz, C., Neumann, S., Scheel, D. et al., 588 Metabolome analysis of biosynthetic mutants reveals a diversity of metabolic changes and allows 589 identification of a large number of new compounds in Arabidopsis. Plant Physiology $590 \quad 2008 ; 147: 2107-20$.

591 Bowler, C., Vardi, A. and Allen, A.E., Oceanographic and biogeochemical insights from diatom 592 genomes. Annu Rev Mar Sci 2010;2:333-65.

593 Bromke, M.A., Giavalisco, P., Willmitzer, L. and Hesse, H., Metabolic analysis of adaptation to 594 short-term changes in culture conditions of the marine diatom Thalassiosira pseudonana. PLoS 595 ONE 2013;8.

596 Brunner, E., Richthammer, P., Ehrlich, H., Paasch, S., Simon, P., Ueberlein, S. et al., Chitin597 based organic networks: an integral part of cell wall biosilica in the diatom Thalassiosira 598 pseudonana. Angew Chem Int Ed 2009;48:9724-7.

599 Bucciarelli, E. and Sunda, W.G., Influence of $\mathrm{CO}_{2}$, nitrate, phosphate, and silicate limitation on 600 intracellular dimethylsulfoniopropionate in batch cultures of the coastal diatom Thalassiosira 601 pseudonana. Limnol Oceanogr 2003;48:2256-65. 
602 Carlson, C.A., 2002. Production and removal processes. In: D.A. Hansell and C.A. Carlson 603 (Editors), Biogeochemistry of marine dissolved organic matter. Academic Press, pp. 91-151.

604 Carpenter, L.J., Malin, G., Liss, P.S. and Kupper, F.C., Novel biogenic iodine-containing 605 trihalomethanes and other short-lived halocarbons in the coastal East Atlantic. Global 606 Biogeochem Cy 2000;14:1191-204.

607 Chambers, M.C., Maclean, B., Burke, R., Amodei, D., Ruderman, D.L., Neumann, S. et al., A 608 cross-platform toolkit for mass spectrometry and proteomics. Nat Biotech 2012;30:918-20.

609 Cui, Q., Lewis, I.A., Hegeman, A.D., Anderson, M.E., Li, J., Schulte, C.F. et al., Metabolite 610 identification via the Madison Metabolomics Consortium Database. Nat Biotech 2008;26:162-4.

611 Daly, R., Rogers, S., Wandy, J., Jankevics, A., Burgess, K.E.V. and Breitling, R., MetAssign: 612 probabilistic annotation of metabolites from LC-MS data using a Bayesian clustering approach. 613 Bioinformatics 2014.

614 de la Cuesta, J.L. and Manley, S.L., Iodine assimilation by marine diatoms and other 615 phytoplankton in nitrate-replete conditions. Limnol Oceanogr 2009;54:1653-64.

616 del Giorgio, P.A. and Cole, J.J., Bacterial growth efficiency in natural aquatic systems. Annu 617 Rev Ecol Syst 1998;29:503-41.

618 Dittmar, T., Koch, B., Hertkorn, N. and Kattner, G., A simple and efficient method for the solid619 phase extraction of dissolved organic matter (SPE-DOM) from seawater. Limnol Oceanogr Meth 620 2008;6:230-5.

621 Dunn, W.B., Broadhurst, D., Begley, P., Zelena, E., Francis-McIntyre, S., Anderson, N. et al., 622 Procedures for large-scale metabolic profiling of serum and plasma using gas chromatography 623 and liquid chromatography coupled to mass spectrometry. Nat Protocols 2011;6:1060-83.

624 Durkin, C.A., Mock, T. and Armbrust, E.V., Chitin in diatoms and its association with the cell 625 wall. Eukaryot Cell 2009:EC.00079-09.

626 Dyhrman, S.T., Jenkins, B.D., Rynearson, T.A., Saito, M.A., Mercier, M.L., Alexander, H. et al., 627 The transcriptome and proteome of the diatom Thalassiosira pseudonana reveal a diverse 628 phosphorus stress response. PLoS ONE 2012;7:e33768.

629 Franklin, D.J., Airs, R.L., Fernandes, M., Bell, T.G., Bongaerts, R.J., Berges, J.A. et al., 630 Identification of senescence and death in Emiliania huxleyi and Thalassiosira pseudonana: Cell 631 staining, chlorophyll alterations, and dimethylsulphoniopropionate (DMSP) metabolism. Limnol 632 Oceanogr 2012;57:305-17.

633 Gilfedder, B.S., Lai, S.C., Petri, M., Biester, H. and Hoffmann, T., Iodine speciation in rain, 634 snow and aerosols. Atmos Chem Phys 2008;8:6069-84. 
635 Gooday, G.W., 1990. The ecology of chitin degradation. In: K.C. Marshall, R.M. Atlas, J.G.

636 Jones and B.B. Jorgensen (Editors), Adv Microb Ecol. Plenum, New York, New York, pp. 387637430.

638 Granum, E., Kirkvold, S. and Myklestad, S.M., Cellular and extracellular production of 639 carbohydrates and amino acids by the marine diatom Skeletonema costatum: diel variations and 640 effects of N depletion. Mar Ecol Prog Ser 2002;242:83-94.

641 Gschwend, P.M., Macfarlane, J.K. and Newman, K.A., Volatile halogenated organic compounds 642 released to seawater from temperate marine macroalgae. Science 1985;227:1033-5.

643 He, F., Emmett, M.R., Håkansson, K., Hendrickson, C.L. and Marshall, A.G., Theoretical and 644 experimental prospects for protein identification based solely on accurate mass measurement. J 645 Proteome Res 2004;3:61-7.

646 Hedges, J.I., 1990. Compositional indicators of organic acid sources and reactions in natural 647 environments. In: E.M. Perdue and E.T. Gjessing (Editors), Organic Acids in Aquatic 648 Ecosystems. John Wiley \& Sons Ltd.

649 Hildebrand, M., Kim, S., Shi, D., Scott, K. and Subramaniam, S., 3D imaging of diatoms with 650 ion-abrasion scanning electron microscopy. J Struct Biol 2009;166:316-28.

651 Hollibaugh, J.T. and Azam, F., Microbial degradation of dissolved proteins in seawater. Limnol 652 Oceanogr 1983;28:1104-16.

653 Horai, H., Arita, M., Kanaya, S., Nihei, Y., Ikeda, T., Suwa, K. et al., MassBank: a public 654 repository for sharing mass spectral data for life sciences. J Mass Spectrom 2010;45:703-14.

655 Hughes, C., Malin, G., Nightingale, P.D. and Liss, P.S., The effect of light stress on the release 656 of volatile iodocarbons by three species of marine microalgae. Limnol Oceanogr 2006;51:284965754.

658 Iijima, Y., Nakamura, Y., Ogata, Y., Tanaka, K., Sakurai, N., Suzuki, T. et al., Metabolite 659 annotations based on the integration of mass spectral information. Plant J 2008;54:949 - 62.

660 Jeuniaux, C. and Voss-Foucart, M.F.o., Chitin biomass and production in the marine 661 environment. Biochem Syst Ecol 1991;19:347-56.

662 Keller, M.D., Kiene, R.P., Matrai, P.A. and Bellows, W.K., Production of glycine betaine and 663 dimethylsulfoniopropionate in marine phytoplankton. II. N-limited chemostat cultures. Mar Biol 664 1999;135:249-57.

665 Kim, S., Kramer, R.W. and Hatcher, P.G., Graphical method for analysis of ultrahigh-resolution 666 broadband mass spectra of natural organic matter, the van krevelen diagram. Anal Chem 667 2003;75:5336-44.

668 Kind, T., Scholz, M. and Fiehn, O., How large is the metabolome? A critical analysis of data 669 exchange practices in chemistry. PLoS ONE 2009;4:e5440. 
670 Kirchman, D.L., 2008. Introduction and Overview. In: D.L. Kirchman (Editor), Microbial 671 Ecology of the Oceans. Wiley-Blackwell, pp. 1-44.

672 Kirchman, D.L. and Hodson, R.E., Metabolic regulation of amino acid uptake in marine waters. 673 Limnol Oceanogr 1986;31:339-50.

674 Kirst, G.O., Salinity tolerance of eukaryotic marine algae. Annu Rev Plant Phys 1990;41:21-53.

675 Kruskal, J.B., Multidimensional scaling by optimizing goodness of fit to a nonmetric hypothesis. 676 Psychometrika 1964;29:1-27.

677 Kuhl, C., Tautenhahn, R., Böttcher, C., Larson, T.R. and Neumann, S., CAMERA: an integrated 678 strategy for compound spectra extraction and annotation of liquid chromatography/mass 679 spectrometry data sets. Anal Chem 2012;84:283-9.

680 Kujawinski, E.B., The impact of microbial metabolism on marine dissolved organic matter.

681 Annu Rev Mar Sci 2011;3:567-99.

682 Kujawinski, E.B. and Behn, M.D., Automated analysis of electrospray ionization Fourier683 transform ion cyclotron resonance mass spectra of natural organic matter. Anal Chem 684 2006;78:4363-73.

685 Kujawinski, E.B., Longnecker, K., Blough, N.V., Del Vecchio, R., Finlay, L., Kitner, J.B. et al., 686 Identification of possible source markers in marine dissolved organic matter using ultrahigh 687 resolution mass spectrometry. Geochim Cosmochim Acta 2009;73:4384-99.

688 Lai, S.C., Williams, J., Arnold, S.R., Atlas, E.L., Gebhardt, S. and Hoffmann, T., Iodine 689 containing species in the remote marine boundary layer: The link to oceanic phytoplankton. 690 Geophys Res Lett 2011;38:L20801.

691 Long, J.Z., Cisar, J.S., Milliken, D., Niessen, S., Wang, C., Trauger, S.A. et al., Metabolomics 692 annotates ABHD3 as a physiologic regulator of medium-chain phospholipids. Nature chemical 693 biology 2011;7:763-5.

694 Longnecker, K. and Kujawinski, E.B., Composition of dissolved organic matter in groundwater. 695 Geochim Cosmochim Acta 2011;75:2752-61.

696 Mather, P.M., 1976. Computational methods of multivariate analysis in physical geography. J. 697 Wiley \& Sons, London, 532 pp.

698 McKenzie, R.A., Franke, F.P. and Dunster, P.J., The toxicity to cattle and bufadienolide content 699 of six Bryophyllum species. Aust Vet J 1987;64:298-301.

700 McKenzie, R.A., Franke, F.P. and Dunster, P.J., The toxicity for cattle of bufadienolide cardiac 701 glycosides from Bryophyllum tubiflorum flowers. Aust Vet J 1989;66:374-6. 
Minor, E.C., Steinbring, C.J., Longnecker, K. and Kujawinski, E.B., Characterization of dissolved organic matter in Lake Superior and its watershed using ultrahigh resolution mass spectrometry. Org Geochem 2012;43:1-11.

Montsant, A., Allen, A.E., Coesel, S., Martino, A.D., Falciatore, A., Mangogna, M. et al., Identification and comparative genomic analysis of signaling and regulatory components in the diatom Thalassiosira pseudonana. J Phycol 2007;43:585-604.

Nelson, D.M., Treguer, P., Brzezinski, M.A., Leynaert, A. and Queguiner, B., Production and dissolution of biogenic silica in the ocean - revised global estimates, comparison with regional data and relationship to biogenic sedimentation. Global Biogeochem Cy 1995;9:359-72.

Norden-Krichmar, T.M., Allen, A.E., Gaasterland, T. and Hildebrand, M., Characterization of the small RNA transcriptome of the diatom, Thalassiosira pseudonana. PLoS ONE 2011;6:e22870.

Nunn, B.L., Aker, J.R., Shaffer, S.A., Tsai, Y.H., Strzepek, R.F., Boyd, P.W. et al., Deciphering diatom biochemical pathways via whole-cell proteomics. Aquat Microb Ecol 2009;55:241-53.

O'Dowd, C.D., Jimenez, J.L., Bahreini, R., Flagan, R.C., Seinfeld, J.H., Hämeri, K. et al., Marine aerosol formation from biogenic iodine emissions. Nature 2002;417:632-6.

Patti, G.J., Yanes, O. and Siuzdak, G., Metabolomics: the apogee of the omics trilogy. Nat Rev Mol Cell Bio 2012;13:263-9.

Paul, C., Barofsky, A., Vidoudez, C. and Pohnert, G., Diatom exudates influence metabolism and cell growth of co-cultured diatom species. Mar Ecol Prog Ser 2009;389:61-70.

Quanbeck, S.M.M., Brachova, L., Campbell, A.A., Guan, X., Perera, A., He, K. et al., Metabolomics as a hypothesis-generating functional genomics tool for the annotation of Arabidopsis thaliana genes of "unknown function". Frontiers in Plant Science 2012;3.

Rabinowitz, J.D. and Kimball, E., Acidic acetonitrile for cellular metabolome extraction from Escherichia coli. Anal Chem 2007;79:6167-73.

Romano, S., Dittmar, T., Bondarev, V., Weber, R.J.M., Viant, M.R. and Schulz-Vogt, H.N., Exo-metabolome of Pseudovibrio sp. FO-BEG1 analyzed by ultra-high resolution mass spectrometry and the effect of phosphate limitation. PLoS ONE 2014;9:e96038.

Rosselló-Mora, R., Lucio, M., Peña, A., Brito-Echeverría, J., López-López, A., Valens-Vadell, M. et al., Metabolic evidence for biogeographic isolation of the extremophilic bacterium Salinibacter ruber. ISME J 2008;2:242-53.

Saiz-Lopez, A., Plane, J.M.C., Baker, A.R., Carpenter, L.J., von Glasow, R., Gómez Martín, J.C. et al., Atmospheric chemistry of iodine. Chem Rev 2011.

Schall, C., Laturnus, F. and Heumann, K.G., Biogenic volatile organoiodine and organobromine compounds released from polar macroalgae. Chemosphere 1994;28:1315-24. 

(CASMI): challenges and solutions. Metabolites 2013;3:517-38.

Shi, X., Gao, W., Chao, S.-h., Zhang, W. and Meldrum, D.R., Monitoring the single-cell stress response of the diatom Thalassiosira pseudonana by quantitative real-time reverse rranscriptionPCR. Appl Environ Microbiol 2013;79:1850-8.

742

Smith, C.A., O'Maille, G., Want, E.J., Qin, C., Trauger, S.A., Brandon, T.R. et al., 2005.

METLIN: A Metabolite Mass Spectral Database 9th International Congress of Therapeutic Drug Monitoring and Clinical Toxicology, Louisville, Kentucky.

Smith, C.A., Want, E.J., O'Maille, G., Abagyan, R. and Siuzdak, G., XCMS: processing mass spectrometry data for metabolite profiling using nonlinear peak alignment, matching, and identification. Anal Chem 2006;78:779 - 87.

Smucker, R.A. and Dawson, R., Products of photosynthesis by marine phytoplankton: Chitin in TCA "protein" precipitates. J Exp Mar Biol Ecol 1986;104:143-52.

Stefels, J., Steinke, M., Turner, S., Malin, G. and Belviso, S., Environmental constraints on the production and removal of the climatically active gas dimethylsulphide (DMS) and implications for ecosystem modelling. Biogeochemistry 2007;83:245-75.

Štrojsová, A. and Dyhrman, S.T., Cell-specific $\beta$-N-acetylglucosaminidase activity in cultures and field populations of eukaryotic marine phytoplankton. FEMS Microbiol Ecol 2008;64:35161.

Suhre, K. and Schmitt-Kopplin, P., MassTRIX: mass translator into pathways. Nucleic Acids Res 2008;36:W481-4.

Sumner, L., Amberg, A., Barrett, D., Beale, M., Beger, R., Daykin, C. et al., Proposed minimum reporting standards for chemical analysis. Metabolomics 2007;3:211-21.

Tautenhahn, R., Bottcher, C. and Neumann, S., Highly sensitive feature detection for high resolution LC/MS. BMC Bioinformatics 2008;9:504.

Tréguer, P., Nelson, D.M., Bennekom, A.J.V., DeMaster, D.J., Leynaert, A. and Quéguiner, B., The silica balance in the world ocean: a reestimate. Science 1995;268:375-9.

Vanelslander, B., Paul, C., Grueneberg, J., Prince, E.K., Gillard, J., Sabbe, K. et al., Daily bursts of biogenic cyanogen bromide $(\mathrm{BrCN})$ control biofilm formation around a marine benthic diatom. Proc Natl Acad Sci USA 2012.

Vidoudez, C. and Pohnert, G., Comparative metabolomics of the diatom Skeletonema marinoi in different growth phases. Metabolomics 2012;8:654-69.

Winder, C.L., Dunn, W.B., Schuler, S., Broadhurst, D., Jarvis, R., Stephens, G.M. et al., Global metabolic profiling of Escherichia coli cultures: an evaluation of methods for quenching and extraction of intracellular metabolites. Anal Chem 2008;80:2939-48. 
772 Wong, G.T.F. and Cheng, X.-H., Dissolved organic iodine in marine waters: Determination, 773 occurrence and analytical implications. Mar Chem 1998;59:271-81.

774

775 


\section{Dissolved organic matter produced by Thalassiosira pseudonana}

Supporting Information

Krista Longnecker, Melissa C. Kido Soule, and Elizabeth B. Kujawinski*.

Woods Hole Oceanographic Institution, Marine Chemistry and Geochemistry, Woods Hole, MA 02543, U.S.A.

TITLE RUNNING HEAD: Phytoplankton metabolomics

*Corresponding author. Mailing address: WHOI MS\#4, Woods Hole, MA 02543. Phone: (508)

289-3493. Fax: (508) 457-2164. E-mail: ekujawinski@whoi.edu 
Table S1. Percent of features with changes in EIC peak heights over time for features found in the samples and absent from the cell-free controls. Only statistically-significant (Model I regressions with $p \leq 0.05$ ) increases or decreases are included in the table. The total \# of features is also shown in Table 1 and is the number of features present in both replicates of either the extracellular or intracellular metabolite samples and absent from the cell-free controls.

\begin{tabular}{lcccc}
\hline & \multicolumn{2}{c}{ Positive } & \multicolumn{2}{c}{ Negative } \\
& Intracellular & Extracellular & Intracellular & Extracellular \\
\hline \% features increased & $4 \%$ & $67 \%$ & $5 \%$ & $25 \%$ \\
\hline$\%$ features decreased & $7 \%$ & $13 \%$ & $6 \%$ & $8 \%$ \\
\hline Total \# features & 3685 & 2203 & 1458 & 1630 \\
\hline
\end{tabular}


Table S2. Summary of the features of interest which could be putatively identified. The table indicates whether the features were detected in positive (pos) or negative (neg) ion mode, and what charged ion was detected. Error indicates the absolute difference between the observed $m / z$ value and the calculated $\mathrm{m} / \mathrm{z}$ value. MS/MS spectra were available for some of the features, and the comments include additional information about each feature.

Reference numbers can be used to find additional information about each compound in the indicated database.

\begin{tabular}{|c|c|c|c|c|c|c|c|}
\hline Putative annotation & $\begin{array}{l}\text { Elemental } \\
\text { Formula } \\
\text { (exact mass) }\end{array}$ & $\begin{array}{l}\text { Ion } \\
\text { mode }\end{array}$ & $\begin{array}{l}\text { Detected } \\
\text { as? }\end{array}$ & $\begin{array}{l}\text { Error } \\
(\mathrm{ppm})\end{array}$ & $\begin{array}{l}\text { MS/MS } \\
?\end{array}$ & Reference numbers & Comments \\
\hline Tri-N-acetylchitotriose & $\begin{array}{l}\mathrm{C}_{24} \mathrm{H}_{41} \mathrm{~N}_{3} \mathrm{O}_{16} \\
(627.248682)\end{array}$ & Pos & {$[\mathrm{M}+\mathrm{H}]^{+}$} & 0.57 & Yes & PubChem CID 444514 & $\begin{array}{l}1 \text { match at METLIN with } \\
\text { MS/MS data corresponding } \\
\text { to the observed MS/MS } \\
\text { data }\end{array}$ \\
\hline Chitobiose & $\begin{array}{l}\mathrm{C}_{16} \mathrm{H}_{28} \mathrm{~N}_{2} \mathrm{O}_{11} \\
(424.169310)\end{array}$ & Pos & {$[\mathrm{M}+\mathrm{H}]^{+}$} & 0.17 & No & KEGG C01674 & $\begin{array}{l}\text { Same retention time as tri- } \\
\text { N-acetylchitotriose }\end{array}$ \\
\hline $\begin{array}{l}\text { Dimethylsulfoniopropionate } \\
\text { (DMSP) }\end{array}$ & $\begin{array}{l}\mathrm{C}_{5} \mathrm{H}_{10} \mathrm{O}_{2} \mathrm{~S} \\
(134.040150)\end{array}$ & Pos & {$[\mathrm{M}+\mathrm{H}]^{+}$} & 0.24 & Yes & KEGG C04022 & $\begin{array}{l}1 \text { match at MMCD; no } \\
\text { match at METLIN }\end{array}$ \\
\hline Bryotoxin A & $\begin{array}{l}\mathrm{C}_{32} \mathrm{H}_{42} \mathrm{O}_{12} \\
(618.267627)\end{array}$ & Pos & {$[\mathrm{M}+\mathrm{H}]^{+}$} & 1.45 & No & KEGG C08853 & $\begin{array}{l}1 \text { match at MMCD; no } \\
\text { match at METLIN }\end{array}$ \\
\hline Organo-iodine compound* & $\begin{array}{l}\mathrm{C}_{22} \mathrm{H}_{22} \mathrm{Cl}_{2} \mathrm{I}_{2} \mathrm{~N}_{2} \mathrm{O}_{7} \\
(749.889361)\end{array}$ & Neg & {$[\mathrm{M}-2 \mathrm{H}+\mathrm{Na}]^{-}$} & 1.88 & No & PubChem CID 11535056 & $\begin{array}{l}\text { No matches at MMCD or } \\
\text { METLIN; found isotopes } \\
\text { for }{ }^{37} \mathrm{Cl}\end{array}$ \\
\hline
\end{tabular}


* The full name for the organo-iodine compound is: Methyl (2R)-2-[[(2R)-2-(3,5-dichloro-4-hydroxyphenyl)-2-[(2-methylpropan-2yl)oxycarbonylamino]acetyl]amino]-2-(4-hydroxy-3,5-diiodophenyl)acetate 
Table S3. Summary of peptide data from the intracellular and extracellular metabolites analyzed in positive or negative ion mode. Both dipeptides and tripeptides were observed. Most of the peptides showed increases in EIC peak heights over the course of the experiment.

\begin{tabular}{lllll}
\hline & & \multicolumn{2}{c}{ Positive } & \multicolumn{2}{c}{ Negative } \\
& Intracellular & Extracellular & Intracellular & Extracellular \\
\hline Total \# of peptide matches & 11 & 88 & 2 & 26 \\
\hline $\begin{array}{l}\text { \# compounds increased during } \\
\text { experiment }\end{array}$ & 6 & 68 & 2 & 23 \\
\hline $\begin{array}{l}\text { \# compounds decreased during } \\
\text { experiment }\end{array}$ & 5 & 20 & 0 & 3 \\
\hline
\end{tabular}


Fig. S1. We used a mixture of metabolites to optimize the LC/FT-ICR-MS parameters. This solution consisted of L-methionine, L-proline, L-arginine, L-glutamic acid, L-glutamine, Lthreonine, caffeine, n-acetyl D-glucosamine, riboflavin, biotin, thymidine, NAD, succinic acid, malic acid, orotic acid, phosphoenolpyruvate, citric acid, glucose 6-phosphate, fructose 1,6bisphosphate, and sodium taurocholate. The total ion chromatograph is shown for (A) the analysis of the metabolite mix and a solvent blank (90:10 water:acetonitrile) in negative ion mode, (B) the analysis of the metabolite mixture and a solvent blank in positive ion mode. The text lists the metabolites (and retention time, in seconds) for each ionization mode.

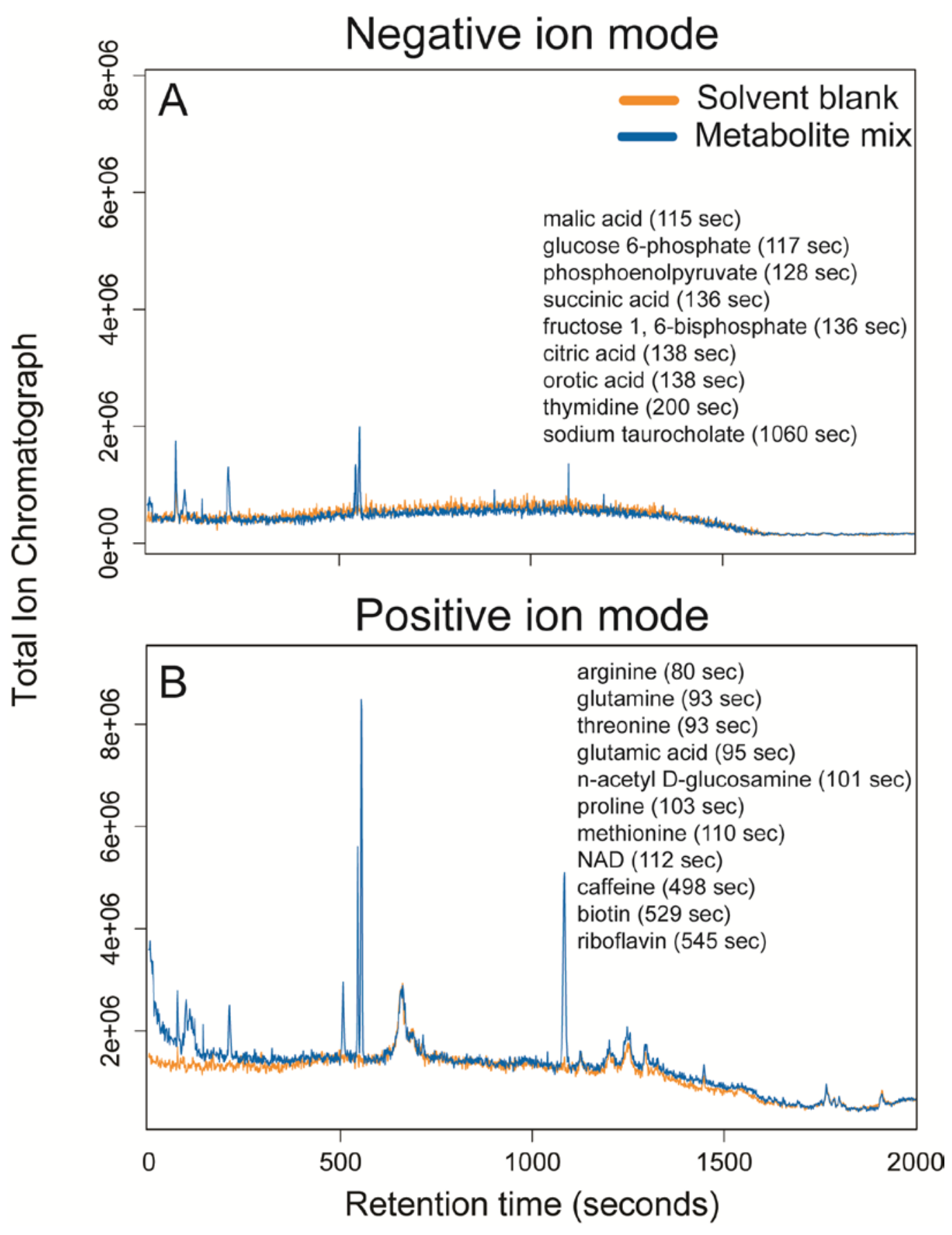

Page S6 
Fig. S2. During the incubation period, there were increases in (A) the abundance of $T$.

pseudonana and (B) the concentration of total organic carbon within the flasks. There were no changes in the cell-free controls over the experiment, nor was there evidence of contamination by heterotrophic bacterial cells. The approximately $200 \mu \mathrm{M}$ of total organic carbon in the cellfree controls is due to the presence of vitamins and EDTA that are required by T. pseudonana for cell growth. (C) There was a decrease in the concentration of nitrate+nitrite in the flasks with $T$. pseudonana indicating the consumption of inorganic nutrients concurrent with increases in cellular abundance. Silicate and phosphate showed similar patterns in concentration (data not shown).
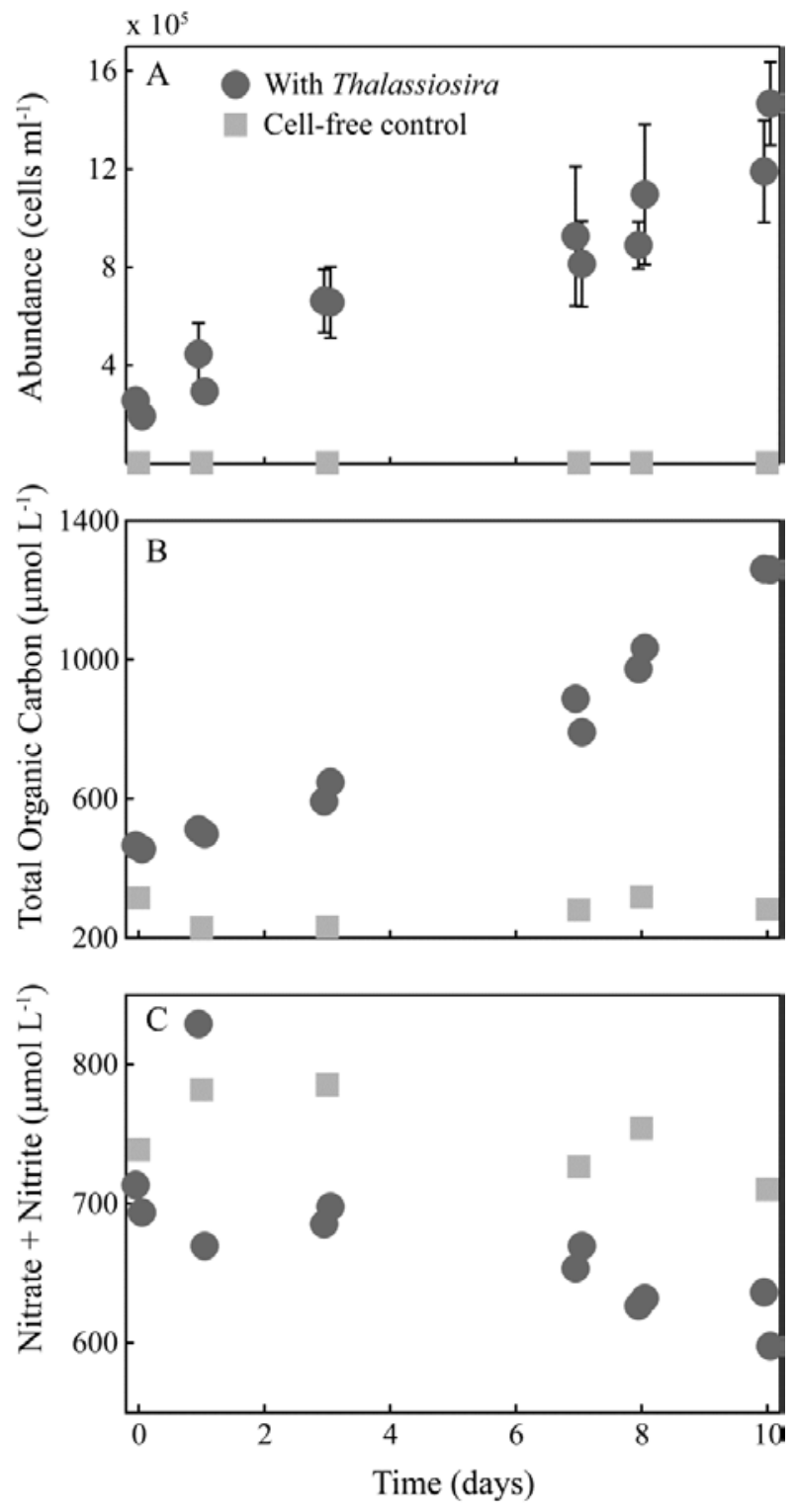
Fig. S3. The number of features (unique combinations of $m / z$ value and retention time) for the extracellular and intracellular metabolites during the experiment from (A) positive ion mode and (B) negative ion mode. The points have been jiggered on the time axis to reduce overlap between sample points. A low number of features was observed in one of the extracellular metabolite samples at day 8 within the positive ion mode data. Inspection of the raw data revealed a problem with sample injection and this sample was not considered further.

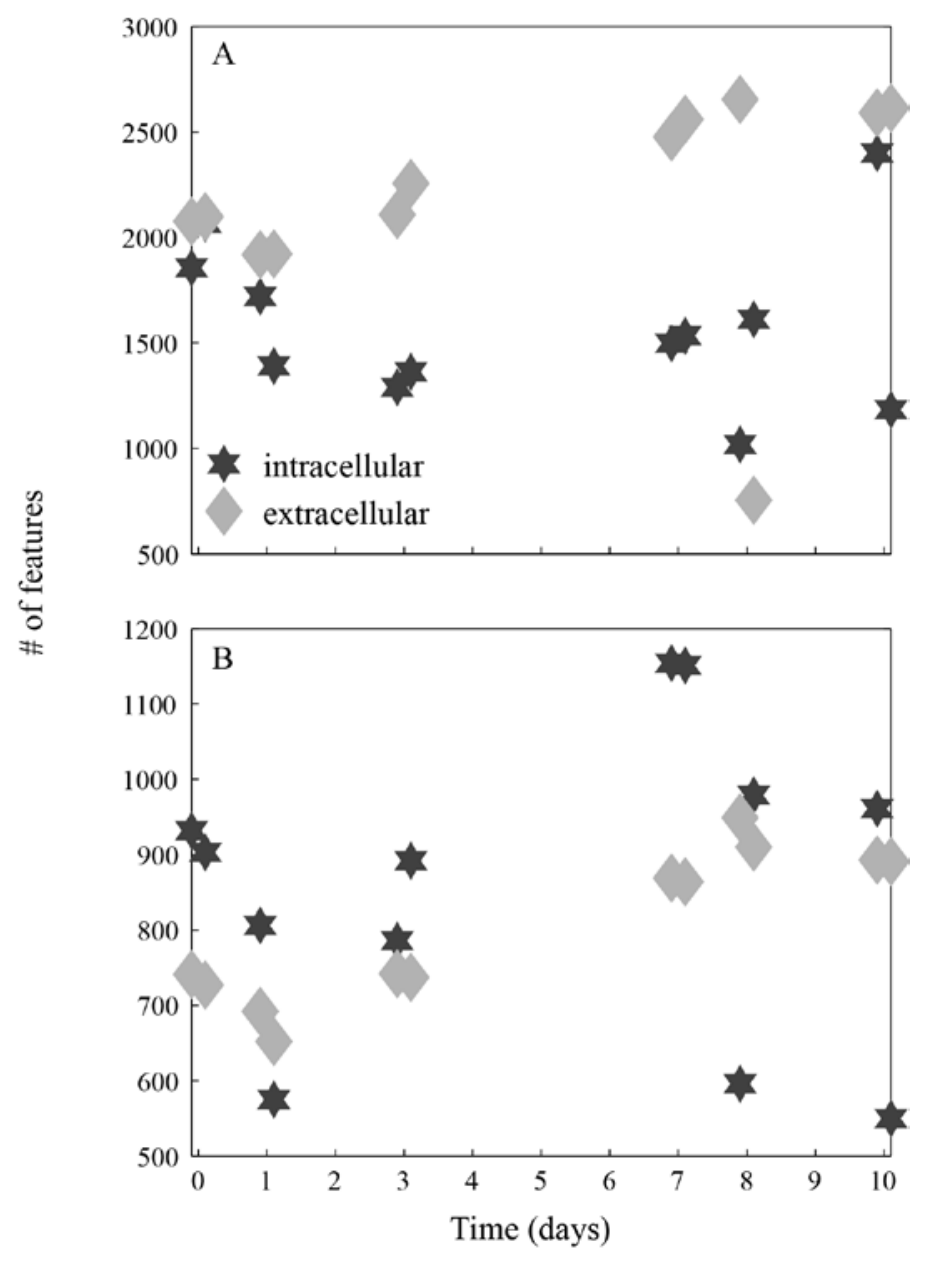


Fig. S4 : Extracted ion chromatogram (EIC) for tri-N-acetylchitotriose which had a measured $\mathrm{m} / \mathrm{z}$ value of 628.52260. XCMS was used to process the data files generated by the LC-FT system. The dark lines are from samples with $T$. pseudonana while the lighter lines are the cell-free controls.

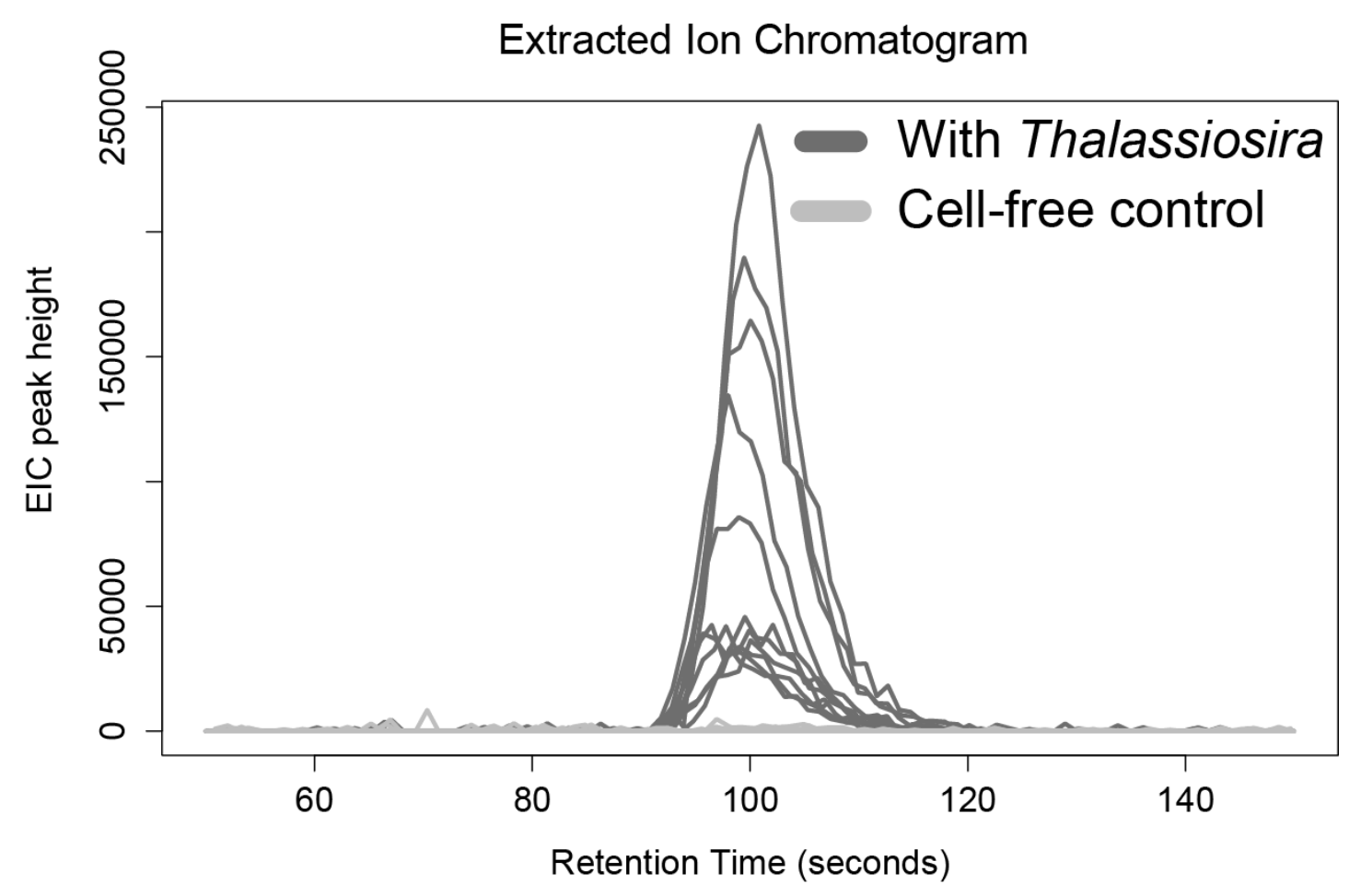


Fig. S5. DMSP was putatively identified in positive ion mode in both the intracellular and extracellular metabolites. The analysis failed for one of the replicates on day 8, and that sample is not plotted on the figure. Note the scale difference in the EIC peak heights between the intracellular and extracellular metabolites. The structure of the compound is also shown.

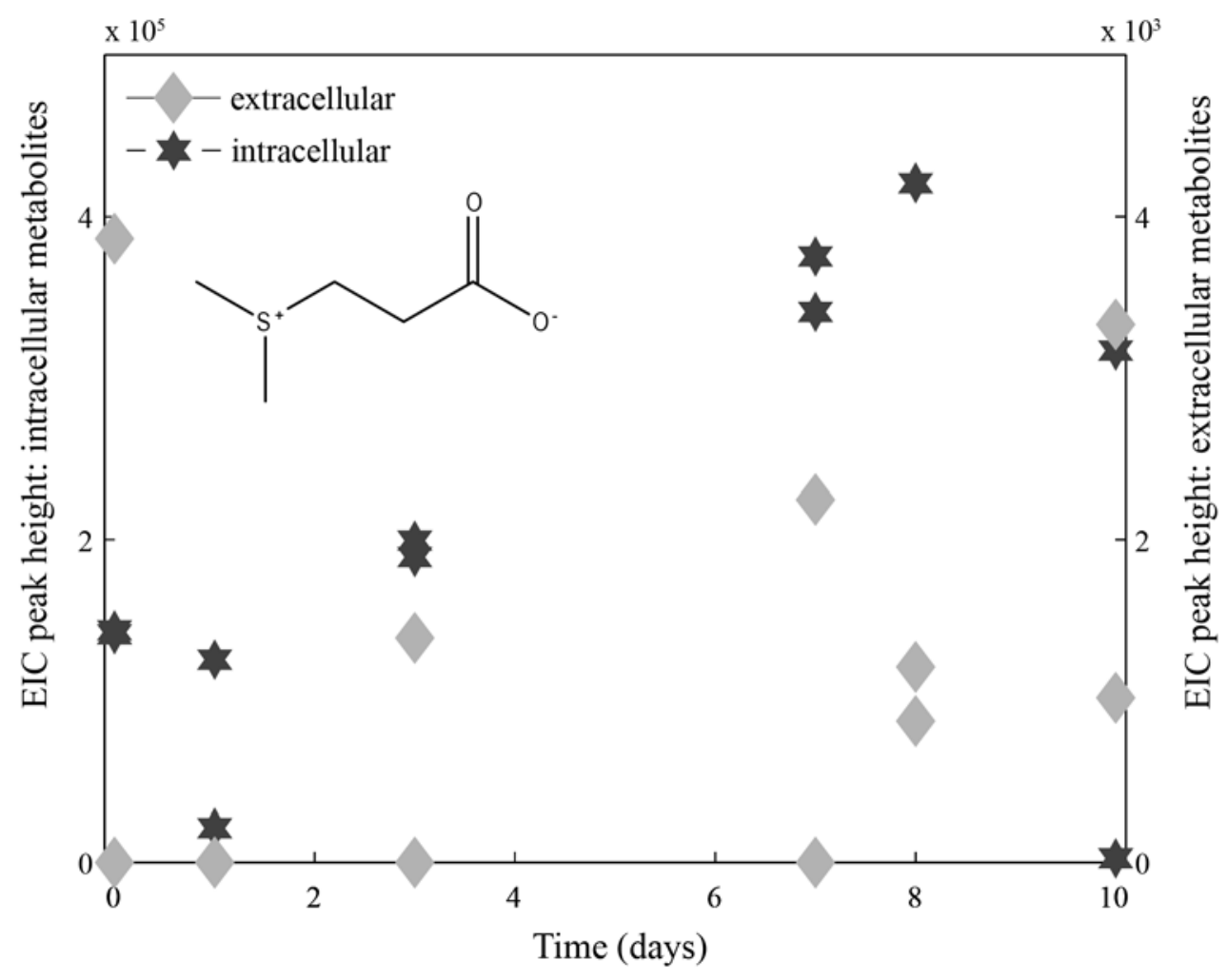


Fig. S6. A feature putatively annotated as bryotoxin A was observed in positive ion mode in both the intracellular and extracellular metabolites. Note the scale difference in the EIC peak heights between the intracellular and extracellular metabolites. The inset shows the structure of bryotoxin A, and the changes in EIC peak heights over the course of the experiment.

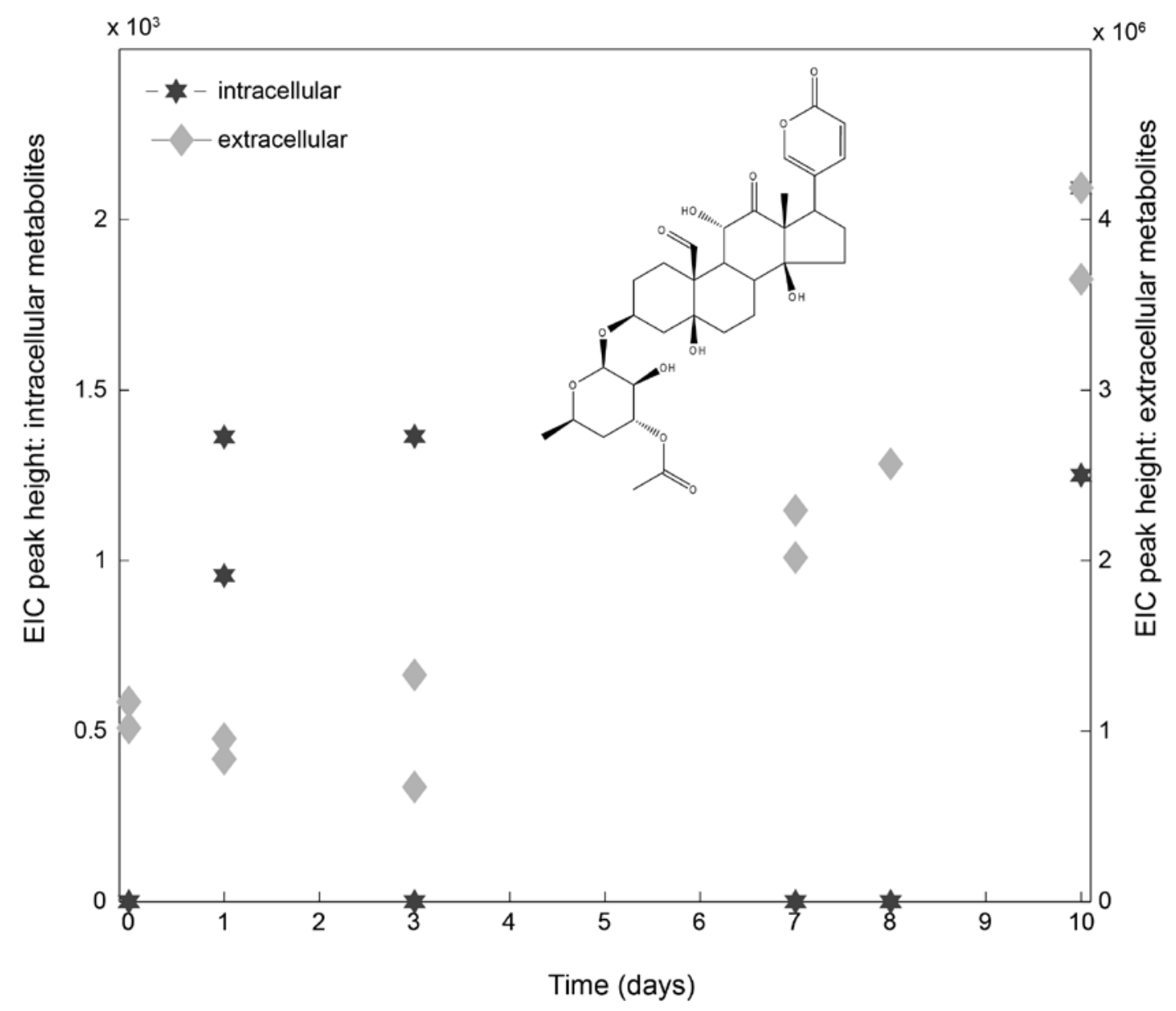


Fig. S7. EIC data for the organo-iodine compound $\left(\mathrm{C}_{22} \mathrm{H}_{22} \mathrm{Cl}_{2} \mathrm{I}_{2} \mathrm{~N}_{2} \mathrm{O}_{7}\right)$ observed in negative ion mode at (A) day zero and (B) day ten of the experiment. The data in green show the compound with two ${ }^{35} \mathrm{Cl}$ molecules, while the data in orange is the EIC data for a feature that putatively has one ${ }^{35} \mathrm{Cl}$ and one ${ }^{37} \mathrm{Cl}$. In the environment, chlorine molecules are $75 \%{ }^{35} \mathrm{Cl}$ and $25 \%{ }^{37} \mathrm{Cl}$, and our data show the ${ }^{35} \mathrm{Cl}$ organo-iodine compound had higher EIC peak heights supporting our putative identification of a compound containing chlorine.

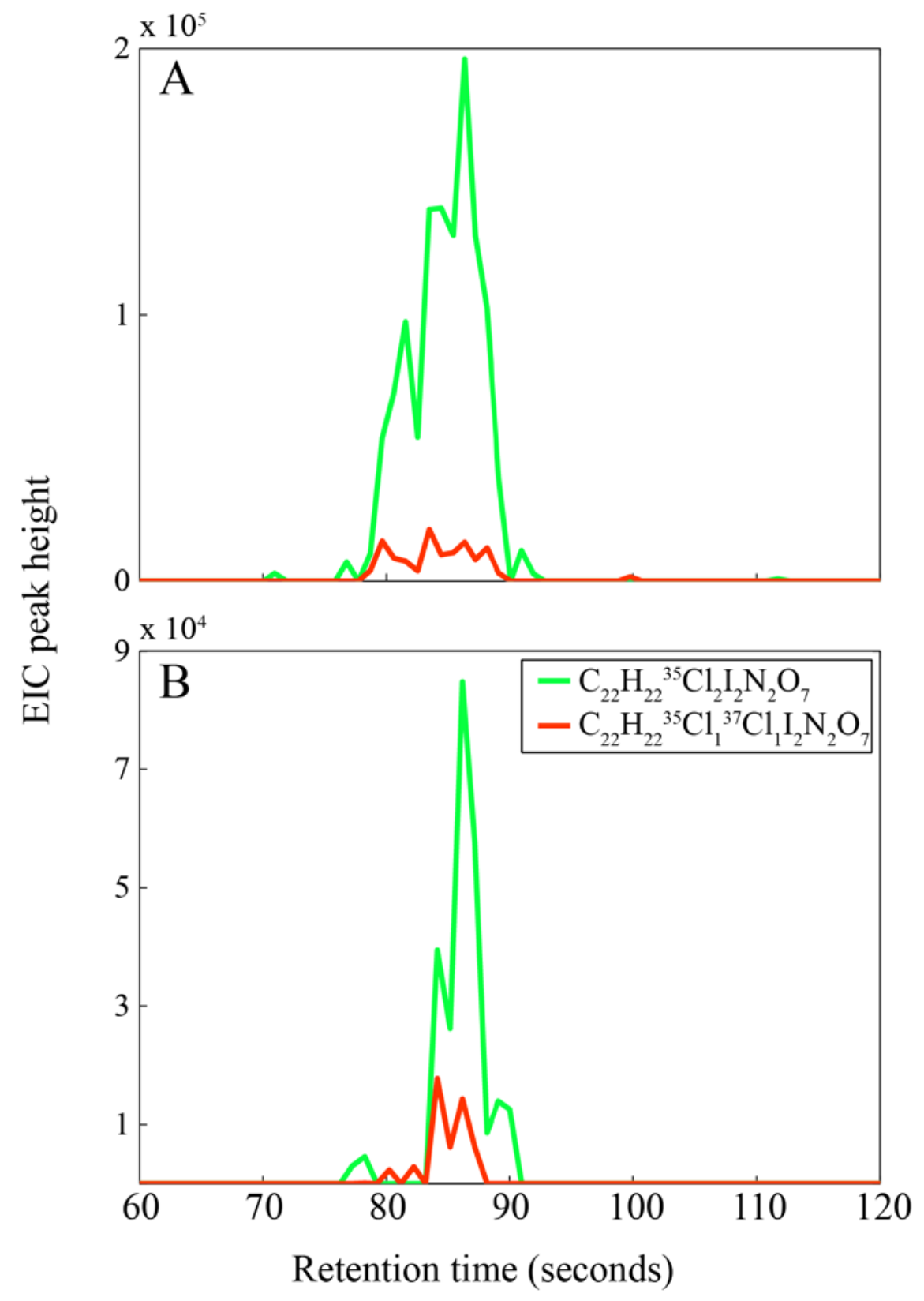

